\title{
Transition Metal-Free Supramolecular Photoredox Catalysis in Water: A Phenoxazine Photocatalyst Encapsulated in V-Shaped Aromatic Amphiphiles
}

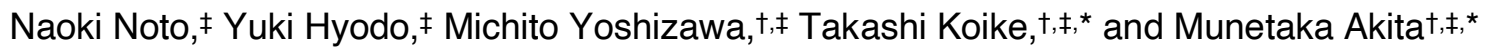 \\ tLaboratory for Chemistry and Life Science, Institute of Innovative Research \\ ‡School of Materials and Chemical Technology, Tokyo Institute of Technology \\ R1-27, 4259 Nagatsuta-cho, Midori-ku, Yokohama 226-8503, Japan \\ Contact details: koike.t.ad@m.titech.ac.jp (TK); makita@res.titech.ac.jp (MA)
}

\section{Table of Contents}

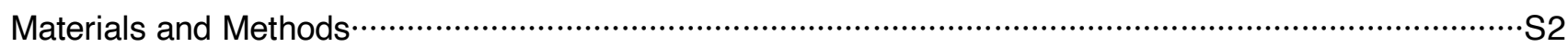

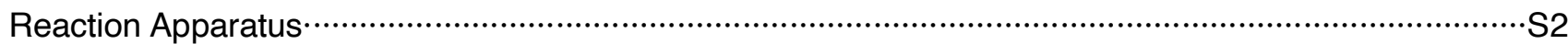

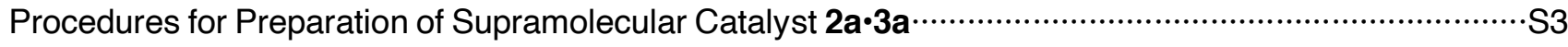

Determination of Concentration, Host-Guest Ratio and Optimized Structure of Supramolecular Catalysts

$2 a \cdot 3$

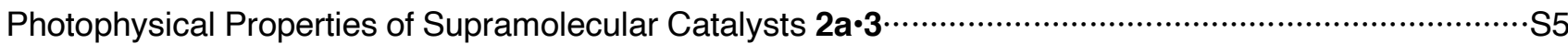

Study on Encapsulation by Other Hosts $\cdots \cdots \cdots \cdots \cdots \cdots$

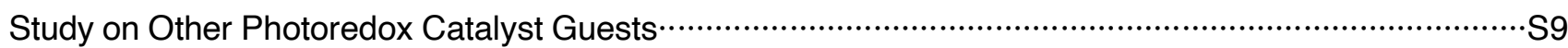

General Procedures for Pinacol Coupling and Characterization of Products ……..................................S11

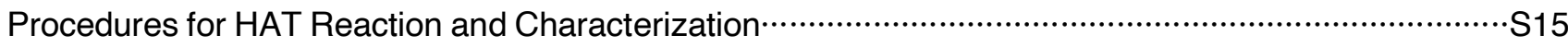

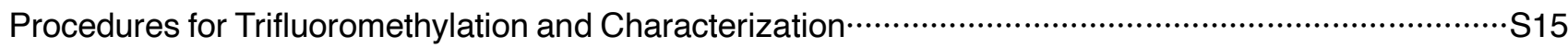

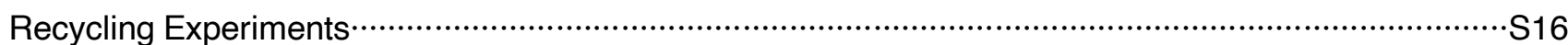

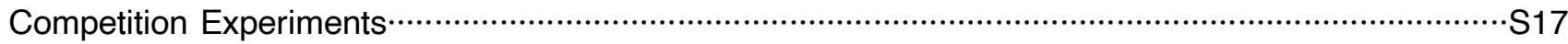

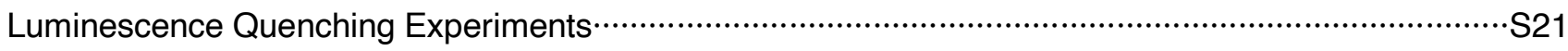

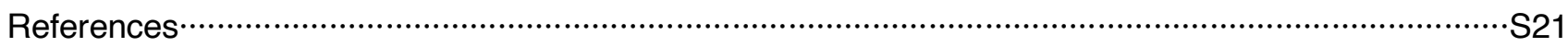

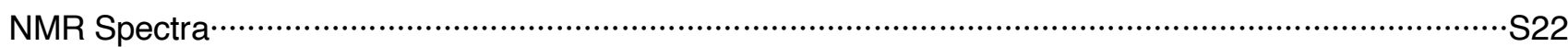




\section{Materials and Methods}

All the chemicals for synthesis of substrates and catalysts were commercially available. Distilled water was purchased from Kanto Chemical Co., Inc. Purification was performed by flash column chromatography on silica gel (Aldrich, silica gel $60 \AA$ ).

Experiments and measurements were carried out with the following apparatuses.

Visible light irradiation: Relyon LED lamp ( $3 \mathrm{~W} \times 2: \lambda=425 \mathrm{~nm}$ ). NMR spectra: Bruker AVANCE-400 (400 $\mathrm{MHz}$ for ${ }^{1} \mathrm{H}$ NMR)(reference of ${ }^{1} \mathrm{H}$ NMR spectra: residual protio impurities in the deuterated solvents). HRMS (ESI-TOF): Bruker micrOTOF II. Recycling preparative HPLC: Japan Analytical Industry Co., Ltd. (JAI) LC-9225 (column: JAIGEL-1H-40 and JAIGEL-2H-40), and Japan Analytical Industry Co., Ltd. (JAI) LC-9201 (column: JAIGEL-1H-20 and JAIGEL-2H-20). UV-Vis: JASCO V-670DS. Fluorescence: HITACHI F-7000. Absolute PL quantum yield: Hamamatsu Photonics C9920-02G with an integration sphere. CV: Hokutodenkou HZ-5000. Excited-state lifetime: Hamamatsu Photonics C7700-ABS-N. Molecular modeling: Material Studio ver 5.5 .

\section{Reaction Apparatus}

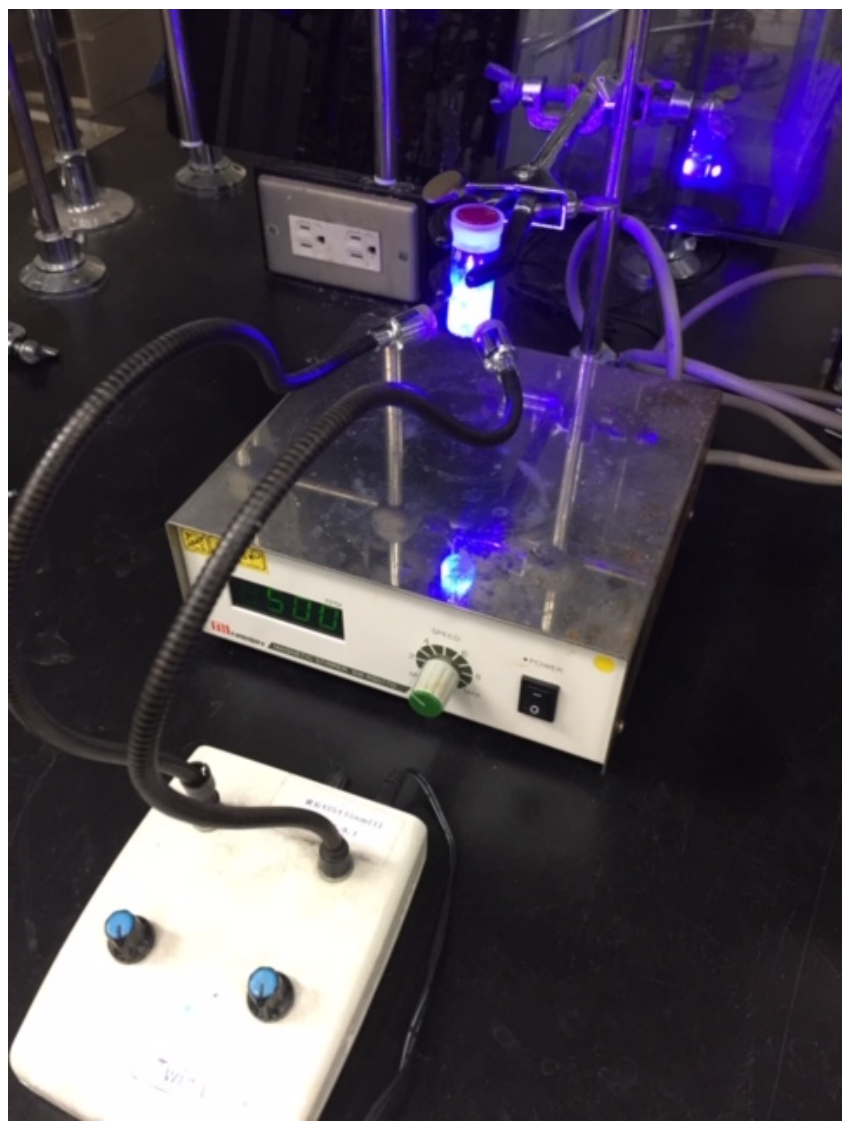

Figure S1. Reaction apparatus. 


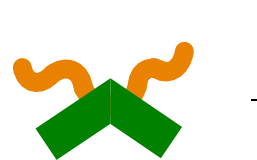

1a

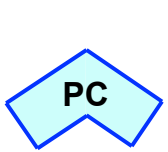

3a
1) grinding

2) $\mathrm{H}_{2} \mathrm{O}, \mathrm{rt}$

3) sonication

4) filtration

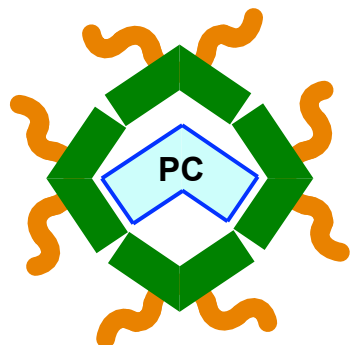

$2 a \cdot 3 a$

A mixture of amphiphilic compound 1a $(6.22 \mathrm{mg}, 9.00 \mu \mathrm{mol})$ and photoredox catalyst 3a (1.53 mg, 2.50 $\mu \mathrm{mol}$ ) was ground manually for 3 min by using an agate mortar and pestle, and then $\mathrm{H}_{2} \mathrm{O}(2.0 \mathrm{~mL})$ was added. The resultant suspension was sonicated $(40 \mathrm{kHz})$ for $10 \mathrm{~min}$. After excess 3a was removed by centrifugation and filtration, a clear yellow solution of $\mathbf{2 a} \cdot \mathbf{3 a}$ was obtained. Formation of the supramolecular catalyst $\mathbf{2 a} \cdot \mathbf{3 a}$ was confirmed by ${ }^{1} \mathrm{H}$ NMR, UV-Vis, and DLS analyses. Other supramolecular catalysts were also prepared by the same procedures.

Determination of Concentration, Host-Guest Ratio and Optimized Structure of Supramolecular Catalysts 2a.3

The concentration and host-guest ratio were estimated by UV-Vis (in DMA) and ${ }^{1} \mathrm{H}$ NMR (in dmso- $d_{6}$ ) analyses after freeze-drying of an aqueous solution of $\mathbf{2 a \cdot 3}$. An optimized structure was depicted from DLS analysis and molecular mechanics (MM).

Determination of concentration of $\mathbf{2} \mathbf{a} \cdot \mathbf{3} \mathbf{a}$ and ratio of $\mathbf{1 a}$ and $\mathbf{3 a}$

(a) UV-vis in $\mathrm{H}_{2} \mathrm{O}$

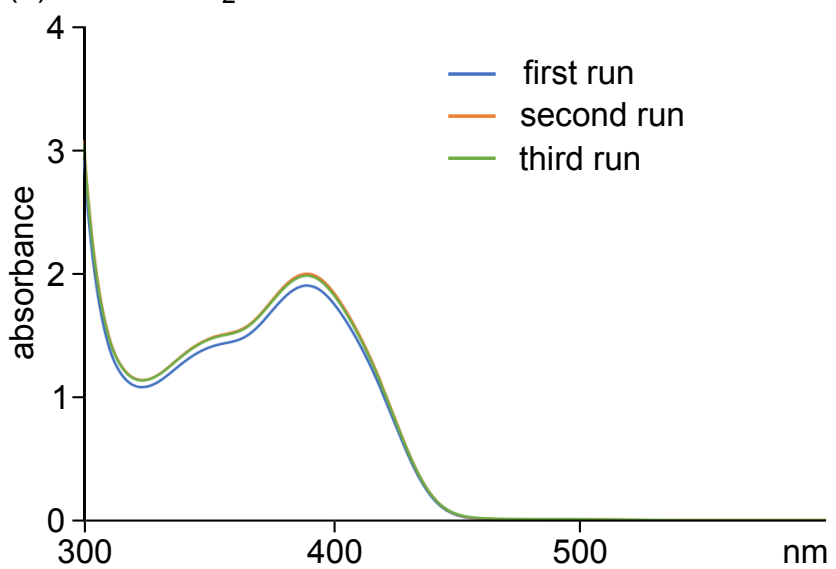

(b) UV-vis in DMA

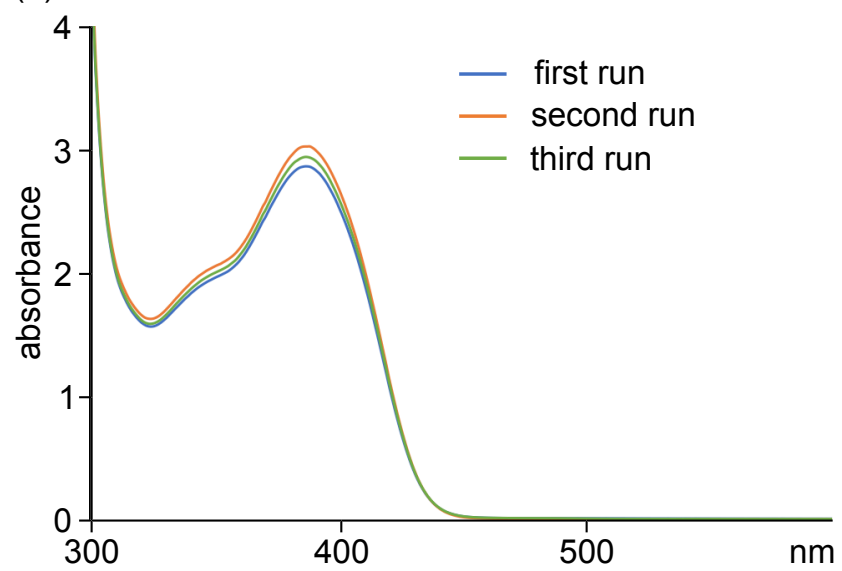

Figure S2. UV-Vis spectra of $\mathbf{2 a} \cdot \mathbf{3 a}(\mathrm{a})$ in $\mathrm{H}_{2} \mathrm{O}$ and (b) in DMA after freeze-drying of an aqueous solution of $2 \mathbf{a} \cdot 3 \mathbf{a}$. 


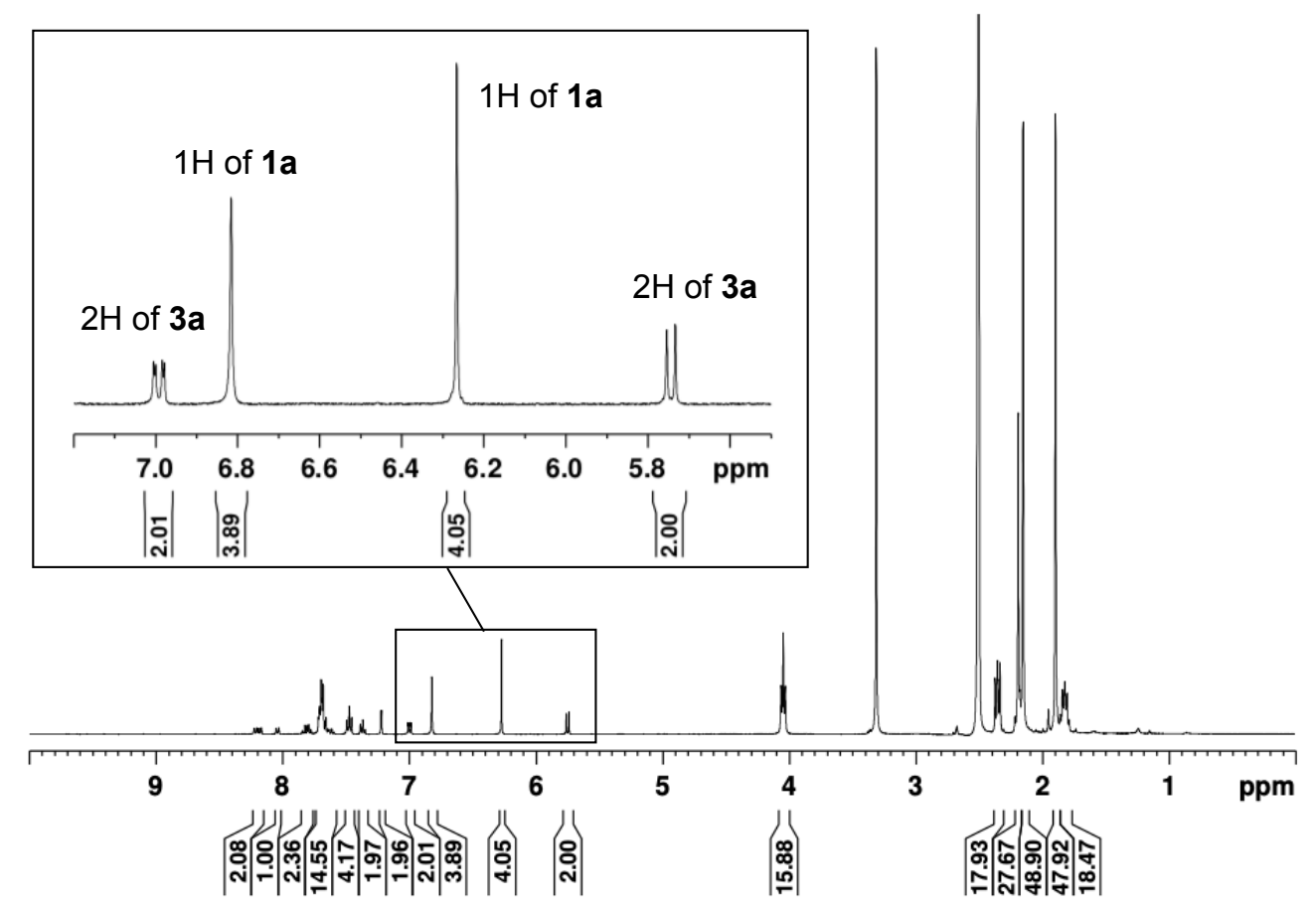

Figure S3. ${ }^{1} \mathrm{H}$ NMR spectrum of $\mathbf{2} \mathbf{a} \cdot \mathbf{3 a}\left(400 \mathrm{MHz}\right.$, dmso- $d_{6}$, rt). Signals of $\mathbf{1 a}$ and $\mathbf{3 a}$ were referred to the reported literatures. ${ }^{1 a, b}$

We carried out UV-Vis analysis for three times due to confirmation of reproducibility by the abovementioned procedures. Absorbance values $(\lambda=388 \mathrm{~nm})$ of each measurement in DMA are as follows.

first run: 2.86351 , second run: 3.02501 , third run: 2.93976

The group of Miyake reported that molar absorption coefficient of $3 a$ in DMA is $2.66 \times 10^{4} \mathrm{M}^{-1} \cdot \mathrm{cm}^{-1} .{ }^{1 b}$ According to the formula $(\mathrm{A}=\varepsilon c /$; : absorbance, $\varepsilon$ : molar absorption coefficient, $c$ : concentration, $l: 0.1$ $\mathrm{cm}$ ), concentration of $3 \mathrm{a}$ is determined to be ca. $1.1 \mathrm{mM}$.

Thus, a solution of $\mathbf{2} \mathbf{a} \cdot \mathbf{3 a}(2 \mathrm{~mL})$ contains approximately $2.2 \mu \mathrm{mol}$ of $\mathbf{3 a}$, assuming that a ratio of $\mathbf{1 a}: \mathbf{3 a}$ is ca. $4: 1$. The ${ }^{1} \mathrm{H}$ NMR spectrum of $\mathbf{2 a} \cdot \mathbf{3 a}$ in $d m s o-d_{6}$ also supported the result as shown in Figure S3.

Observation of size and an optimized structure of $\mathbf{2 a} \cdot \mathbf{3 a}$
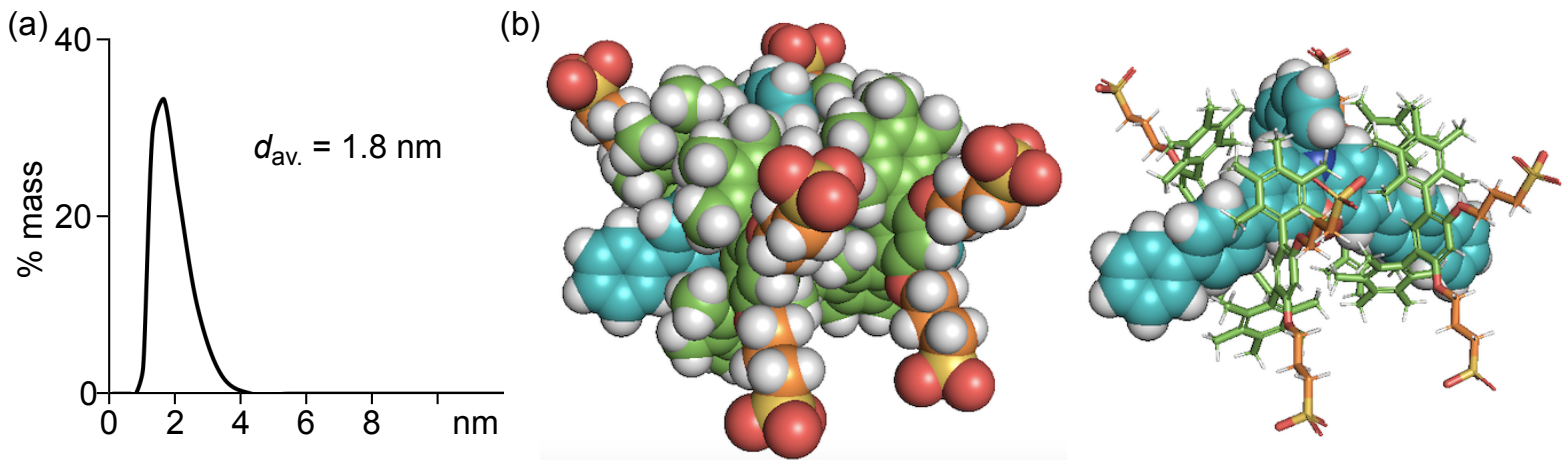

Figure S4. (a) DLS chart of $\mathbf{2 a} \cdot \mathbf{3 a}$ and (b) an optimized structure of $\mathbf{2 a} \cdot \mathbf{3 a}$. 
Studies on single inclusion complex

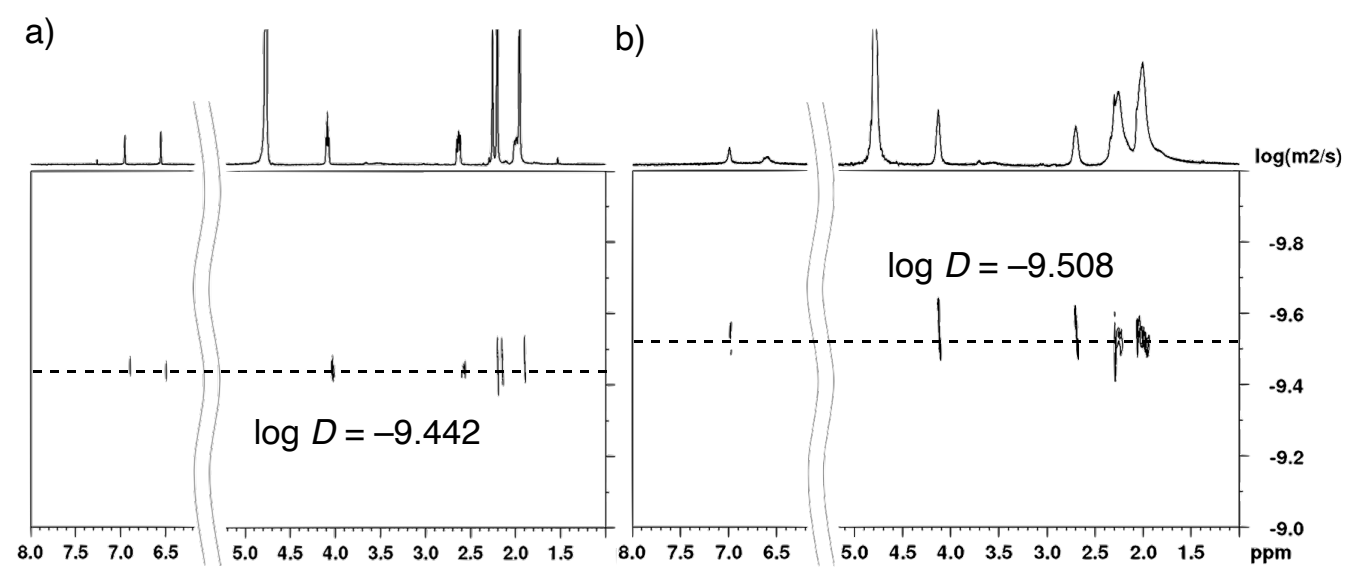

Figure S5. DOSY NMR spectra (400 MHz, rt) of a) only host and b) $\mathbf{2 a} \cdot \mathbf{3 a}$ in $\mathrm{D}_{2} \mathrm{O}$ 
Determination of concentration of $\mathbf{2} \mathbf{a} \cdot \mathbf{3} \mathbf{b}$

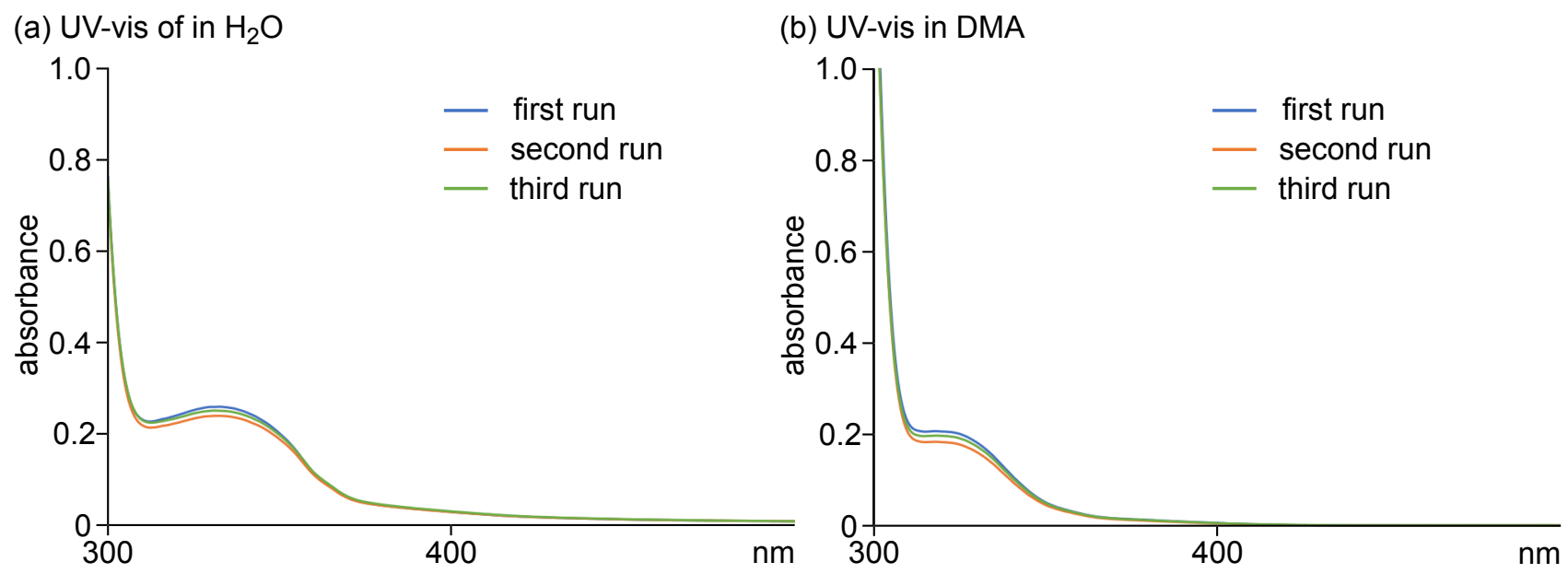

Figure S6. UV-Vis spectra of $\mathbf{2 a \cdot 3 b}(\mathbf{a})$ in $\mathrm{H}_{2} \mathrm{O}$ and (b) in DMA after freeze-drying of an aqueous solution of $2 a \cdot 3 b$.

$$
\begin{aligned}
& \text { Absorbance values }(\lambda=323 \mathrm{~nm}) \\
& \text { first run: } 0.204913 \text {, second run: } 0.181512 \text {, third run: } 0.195091
\end{aligned}
$$

Reported molar absorption coefficient: $7.85 \times 10^{3}$

According to the above-mentioned procedures, concentration of $\mathbf{3 b}$ was determined to be ca. $0.25 \mathrm{mM}$.

\section{Photophysical Properties of Supramolecular Catalysts 2a・3}

\begin{tabular}{|c|c|c|c|}
\hline variations & $\lambda_{\mathrm{em}, \max }(\mathrm{nm})^{\mathrm{b}}$ & $\Phi(\%)^{b}$ & $\tau(\mathrm{ns})^{\mathrm{c}}$ \\
\hline $\mathbf{2 a} \cdot \mathbf{3} \mathbf{a}$ in $\mathrm{H}_{2} \mathrm{O}$ & 480 & 1 st: $0.9,2^{\text {nd: }} 0.9,3^{\text {rd: }} 0.8$ & 3 \\
\hline $\mathbf{2} \mathbf{a} \cdot \mathbf{3} \mathbf{a}+\mathrm{Et}_{3} \mathrm{~N}(10 \mathrm{mM})$ in $\mathrm{H}_{2} \mathrm{O}$ & 477 & 1 st: $2.4,2^{\text {nd: }}: 2.3,3^{\text {rd: }} 2.4$ & 3 \\
\hline $\mathbf{3 a}$ in toluene & 472 & 1 st: $2.3,2^{\text {nd: }} 2.3,3^{\text {rd: }} 2.3$ & 3 \\
\hline 3a in DMF & 527 & $1^{\text {st: }} 2.8,2^{\text {nd: }}: 2.7,3^{\text {rd: }} 2.8$ & 5 \\
\hline $\mathbf{2 a} \cdot \mathbf{3 b}$ in $\mathrm{H}_{2} \mathrm{O}$ & 438 & $1^{\text {st: }} 1.3,2^{\text {nd: }} 1.3,3^{\text {rd: }} 1.1$ & 2 \\
\hline $\mathbf{3 b}$ in toluene & 477 & $1^{\text {st: }} 1.3,2^{\text {nd: }} 1.3,3^{\text {rd: }} 1.3$ & 3 \\
\hline 3b in DMF & 538 & $1^{\text {st: }}: 2.2,2^{\text {nd: }}: 2.2,3^{\text {rd: }} 2.2$ & 10 \\
\hline
\end{tabular}

Table S1. Photophysical data under several conditions. ${ }^{a}$

$\mathrm{a}[\mathbf{3 a}]=1.1 \mathrm{mM},[\mathbf{3 b}]=0.25 \mathrm{mM}, \mathrm{rt}$, air. ${ }^{\mathrm{b}} \lambda_{\mathrm{ex}}=390 \mathrm{~nm}$ for $\mathbf{2} \mathbf{a} \cdot \mathbf{3} \mathbf{a}$ and $\mathbf{3 a}, \lambda_{\mathrm{ex}}=350 \mathrm{~nm}$ for $\mathbf{2} \mathbf{a} \cdot \mathbf{3} \mathbf{b}$ and $\mathbf{3 b}$, measurements were performed three times. ${ }^{\circ} \lambda_{\mathrm{ex}}=355 \mathrm{~nm}$. 


\section{Study on Encapsulation by Other Hosts}<smiles>Cc1c(C)c(C)c(-c2cc(-c3c(C)c(C)c(C)c(C)c3C)c(OCCCS(=O)(=O)[O-])cc2OCCCO)c(C)c1C</smiles>

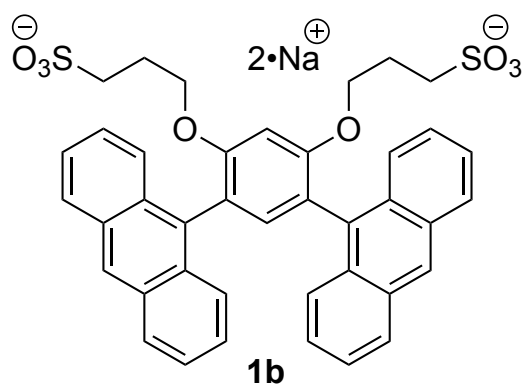

$\mathrm{H}_{2} \mathrm{O}$ solutions of other supramolecular catalysts were prepared according to the above-mentioned procedures. $9.00 \mathrm{mmol}$ of other hosts (1b, SDS, $\beta-C D$ and $\gamma-C D)$ were used instead of $\mathbf{1 a}$.

(a) (SDS) $n$

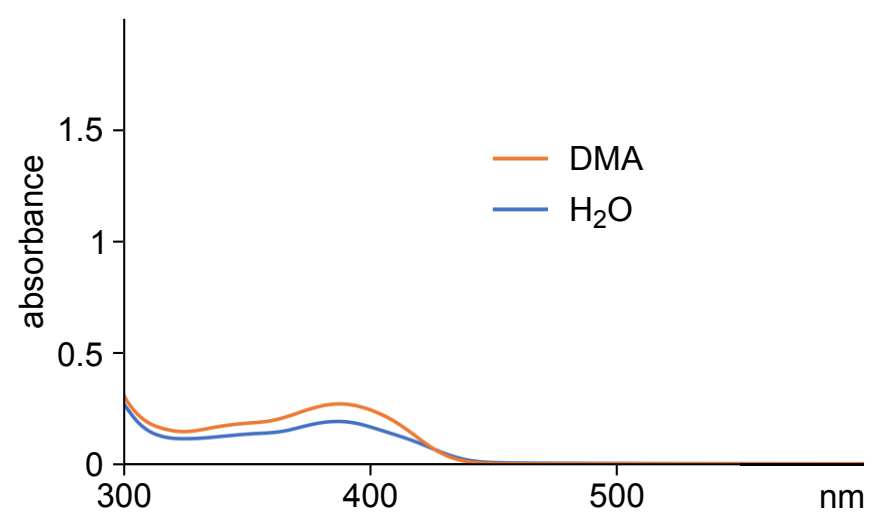

Figure S7. UV-Vis spectra of $(\mathrm{SDS})_{n} \cdot \mathbf{3 a}$ in $\mathrm{H}_{2} \mathrm{O}$ and in DMA after freeze-drying.

- From UV-Vis spectrum (Abs. $=0.269395$ at $388 \mathrm{~nm})$ and molar absorption coefficient of $3 \mathbf{a}(\varepsilon=2.66 \mathrm{x}$ $\left.10^{4} \mathrm{M}^{-1} \cdot \mathrm{cm}^{-1}\right),{ }^{1 b}$ concentration of $3 a$ was determined to be $0.101 \mathrm{mM}$.

(a) $2 b$

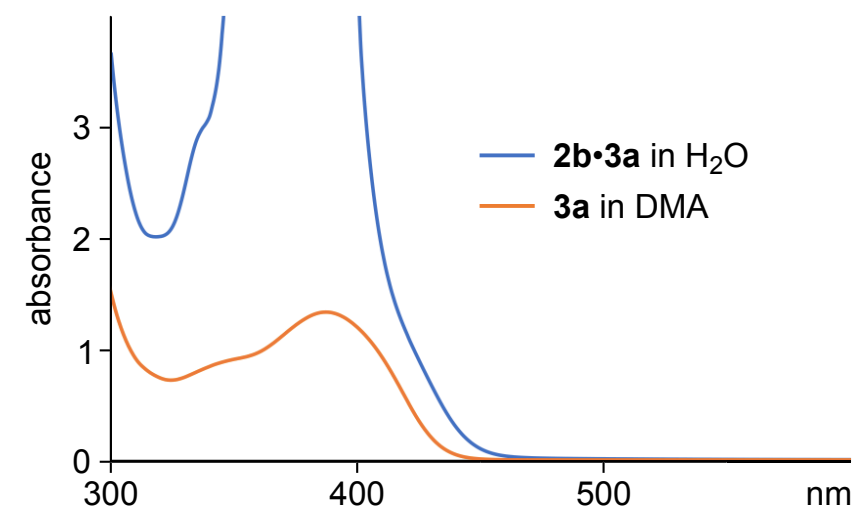

Figure S8. UV-Vis spectra of $\mathbf{2} \mathbf{b} \cdot \mathbf{3} \mathbf{a}$ in $\mathrm{H}_{2} \mathrm{O}$ and $\mathbf{3 a}$ in DMA. 


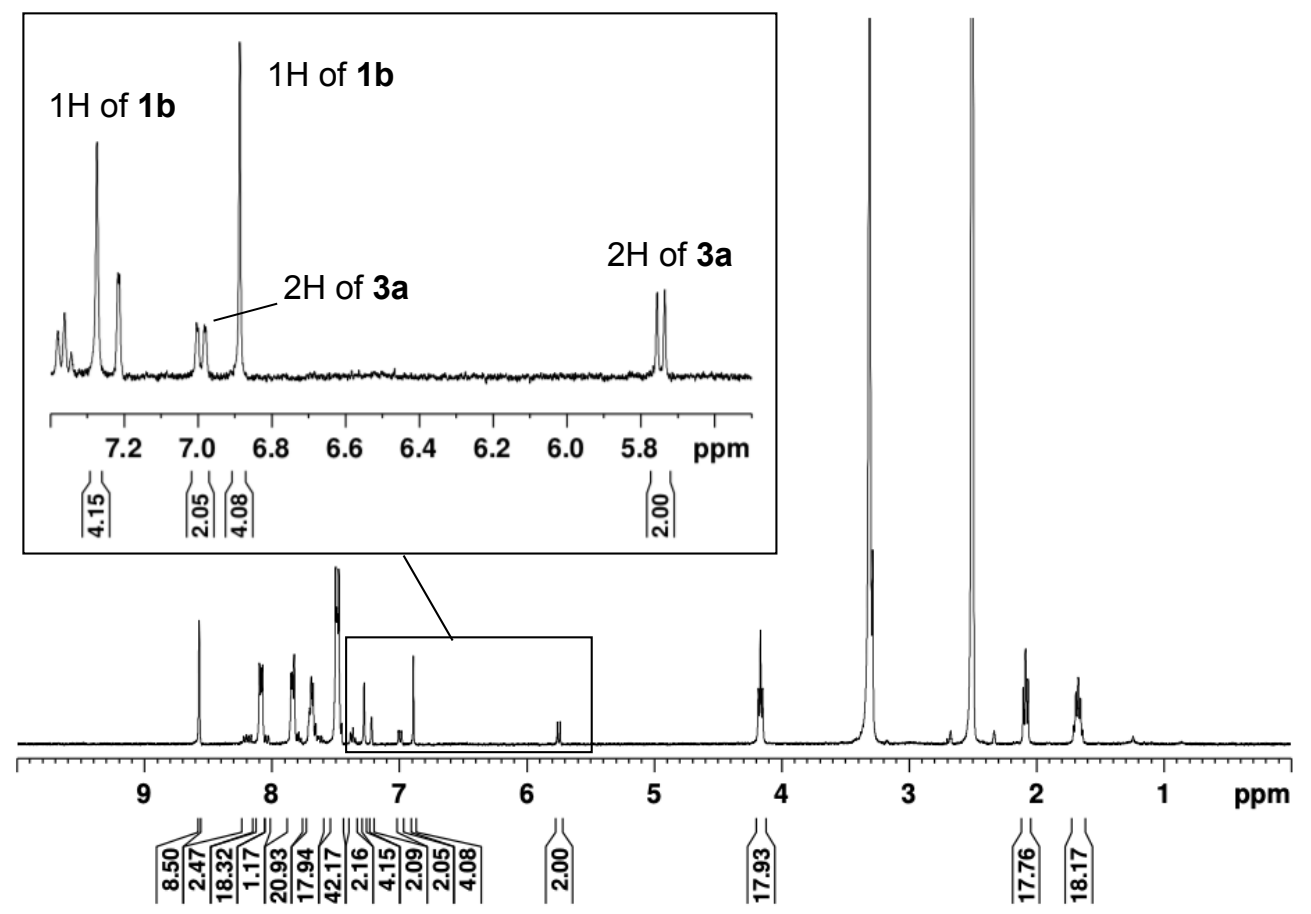

Figure 59. ${ }^{1} \mathrm{H}$ NMR spectrum of $\mathbf{2} \mathbf{b} \cdot \mathbf{3 a}\left(400 \mathrm{MHz}\right.$, dmso- $d_{6}$, rt). Signals of $\mathbf{1 b}$ and $\mathbf{3 a}$ were referred to the reported literatures. ${ }^{1 \mathrm{~b}, \mathrm{c}}$

- From the UV-Vis spectrum (Figure S7), absorption of $\mathbf{2 b}$ largely overlapped to that of $\mathbf{3 a}$, so we could not determine concentration of $3 a$. Meanwhile, since the ${ }^{1} \mathrm{H}$ NMR spectrum (Figure S8) showed that a ratio of $\mathbf{1 b}$ and $\mathbf{3 a}$ is approximately $4: 1$, and then concentration of $\mathbf{3 a}$ was estimated to ca. $1.1 \mathrm{mM}$, which is almost the same as concentration of $\mathbf{3 a}$ in the case of $\mathbf{2} \mathbf{a} \cdot \mathbf{3} \mathbf{a}$.

Table S2. Comparison of the reactivity.<smiles>O=C(F)c1ccccc1</smiles>

4a

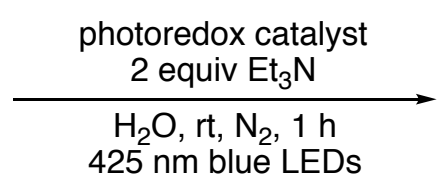

$425 \mathrm{~nm}$ blue LEDs<smiles>OC(c1ccccc1)C(O)c1ccccc1</smiles>

$5 a$

\begin{tabular}{|c|c|}
\hline photoredox catalyst & yield (\%) \\
\hline $2 \mathbf{a} \cdot 3 \mathbf{a}(1 \mathrm{~mol} \%)$ & $92 \%$ \\
\hline $\mathbf{2 b} \cdot \mathbf{3 a}(1 \mathrm{~mol} \%)$ & $32 \%$ \\
\hline$(\mathrm{SDS})_{n} \cdot 3 \mathbf{a}(0.09 \mathrm{~mol} \%)$ & $20 \%$ \\
\hline
\end{tabular}

- As a result of comparison of reactivity (Table S2), $\mathbf{2} \mathbf{b} \cdot \mathbf{3} \mathbf{a}$ showed much lower reactivity than $\mathbf{2 a \cdot 3 a}$. Overlap of absorption hinders excitation of $\mathbf{3} \mathbf{a}$ in the cavity of $\mathbf{2} \mathbf{b}$, leading to a lower yield despite the good encapsulation ability of $\mathbf{2} \mathbf{b}$.

- SDS could uptake only the small amount of $\mathbf{3 a}$, and it is one of the reasons for low conversion of $\mathbf{4 a}$. 


\section{Study on Other Photoredox Catalyst Guests}

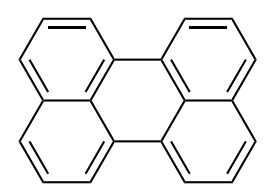

12

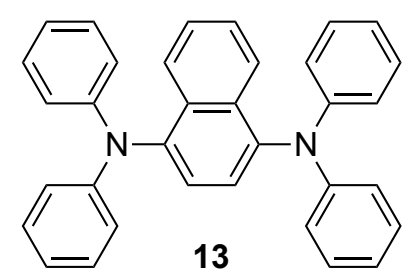

13

A $\mathrm{H}_{2} \mathrm{O}$ solution of $\mathbf{2 a \cdot 1 2}$ and $\mathbf{2 a \cdot 1 3}$ were prepared according to the above-mentioned procedures. Photocatalysts $12(0.63 \mathrm{mg}, 2.50 \mathrm{mmol})$ and $13(1.16 \mathrm{mg}, 2.50 \mathrm{mmol})$ were used instead of $3 a$.

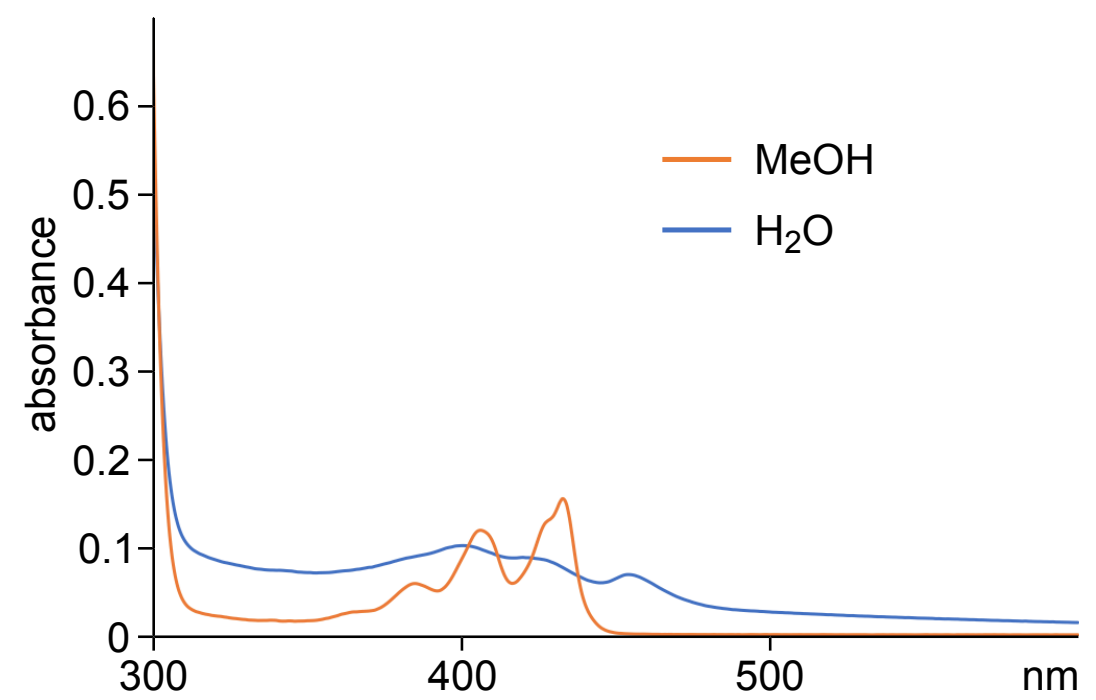

Figure S10. UV-Vis spectra of $\mathbf{2 \cdot 1 2}$ in $\mathrm{H}_{2} \mathrm{O}$ and in $\mathrm{MeOH}$ after freeze-drying.

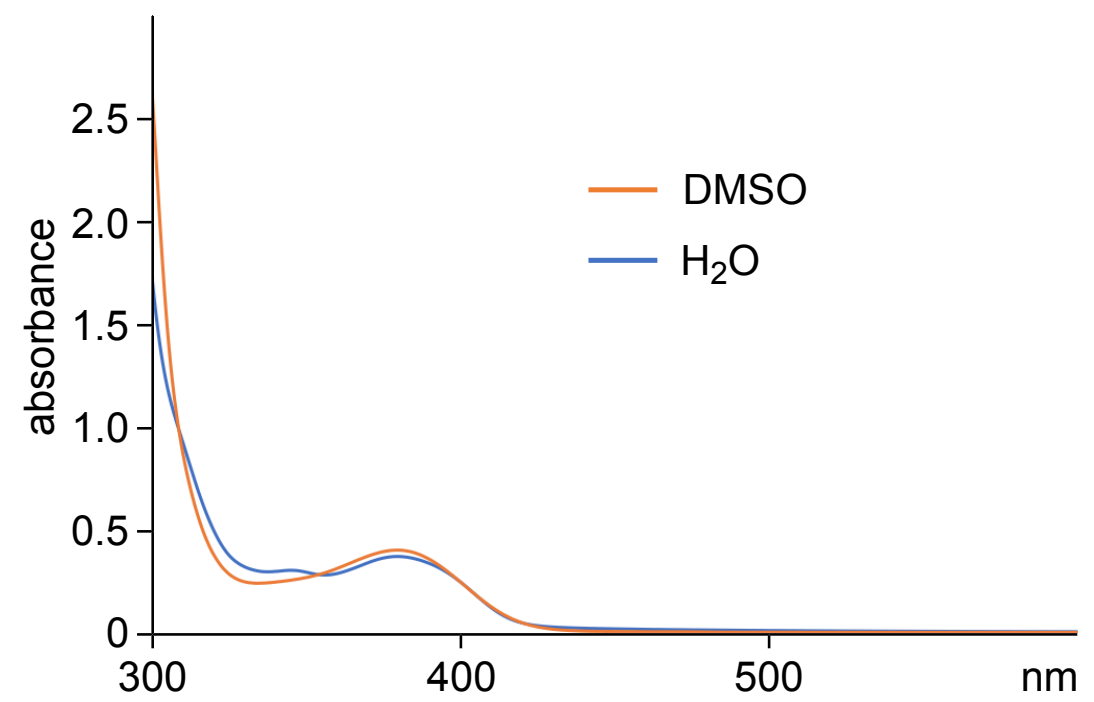

Figure S11. UV-Vis spectra of $\mathbf{2 a} \cdot \mathbf{1 3}$ in $\mathrm{H}_{2} \mathrm{O}$ and in DMSO after freeze-drying.

- From UV-Vis spectrum (Abs. $=0.154266$ at $433 \mathrm{~nm})$ and molar absorption coefficient of $12(\varepsilon=4.06 \mathrm{x}$ $\left.10^{4} \mathrm{M}^{-1} \cdot \mathrm{cm}^{-1}\right),{ }^{3}$ concentration of 12 was determined to be $0.0380 \mathrm{mM}$. 
- From UV-Vis spectrum (Abs. $=0.399554$ at $380 \mathrm{~nm})$ and molar absorption coefficient of $13(\varepsilon=9.04 \mathrm{x}$ $\left.10^{3} \mathrm{M}^{-1} \cdot \mathrm{cm}^{-1}\right),{ }^{4}$ concentration of $\mathbf{1 3}$ was determined to be $0.442 \mathrm{mM}$.

Table S3. Comparison of the reactivity.

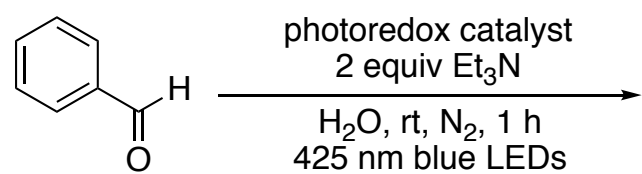

$4 a$<smiles>OC(c1ccccc1)C(O)c1ccccc1</smiles>

$5 a$

\begin{tabular}{|c|c|}
\hline photoredox catalyst & yield (\%) \\
\hline $\mathbf{2 a} \cdot \mathbf{3 a}(1 \mathrm{~mol} \%)$ & $92 \%$ \\
\hline $\mathbf{2 a} \cdot \mathbf{1 2}(0.03 \mathrm{~mol} \%)$ & $0 \%$ \\
\hline $\mathbf{2 a} \cdot \mathbf{1 3}(0.4 \mathrm{~mol} \%)$ & $22 \%$ \\
\hline
\end{tabular}




\section{General Procedures for Pinacol Coupling and Characterization of Products}

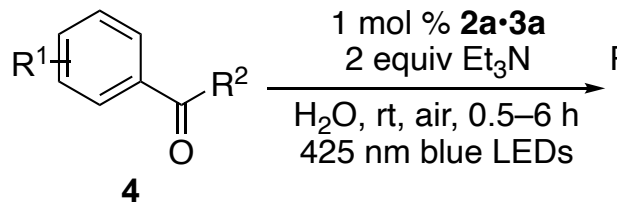<smiles>[R][R]C([R])(c1ccc([R])cc1)C([R])(O)c1cc[R1]([H])cc1</smiles>

A $4 \mathrm{~mL}$ sample bottle was charged with aldehyde $4(0.220 \mathrm{mmol})$, triethylamine $(44.5 \mathrm{mg}, 0.440 \mathrm{mmol})$, and $\mathrm{H}_{2} \mathrm{O}$ solution of $\mathbf{2 a} \cdot \mathbf{3 a}$ (ca. $1.1 \mathrm{mM}, 2 \mathrm{~mL}$ ), and then it was placed at a distance of $1 \mathrm{~cm}$ away from blue LED lamps $(\lambda=425 \mathrm{~nm})$. The mixture was irradiated with stirring $(500 \mathrm{rpm})$ and cooling by a fan for $0.5-6 \mathrm{~h}$. Then, water was added, and the resulting mixture was extracted with $\mathrm{Et}_{2} \mathrm{O}$. The organic layer was dried over $\mathrm{Na}_{2} \mathrm{SO}_{4}$, and evaporated. The desired product was obtained after purification.

\section{1,2-Diphenylethane-1,2-diol (5a)}<smiles>OC(c1ccccc1)C(O)c1ccccc1</smiles>

$5 a$

According to the general procedures (reaction time $=1 \mathrm{~h}$ ), benzaldehyde $4 \mathrm{a}(23.3 \mathrm{mg}, 0.220 \mathrm{mmol}$ ) afforded $5 \mathrm{a}$ as a white solid $(21.2 \mathrm{mg}, 0.0989 \mathrm{mmol}, 90 \%$, meso:dl = 1.2:1) after purification by flash column chromatography on silica-gel (hexane:ethyl acetate $=2: 1$ ).

Spectral data is in agreement with the reported literature.2a

${ }^{1} \mathrm{H}$ NMR $\left(400 \mathrm{MHz}, \mathrm{CDCl}_{3}, \mathrm{rt}\right): \delta 7.34-7.13$ (20H of meso and $\left.d l\right), 4.84$ (s, 2H of meso), 4.73 (s, 2H of $\left.d l\right)$, $2.78(\mathrm{~s}, 2 \mathrm{H}$ of $d l), 2.15(\mathrm{~s}, 2 \mathrm{H}$ of meso).

1,2-Di-p-tolylethane-1,2-diol (5b)

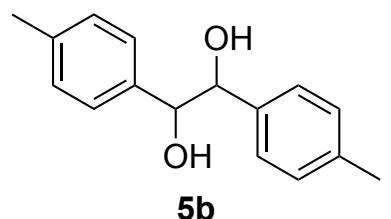

According to the general procedures (reaction time $=1 \mathrm{~h}$ ), $p$-tolualdehyde $\mathbf{4 b}(26.4 \mathrm{mg}, 0.220 \mathrm{mmol}$ ) afforded $\mathbf{5 b}$ as a white solid $(24.7 \mathrm{mg}, 0.102 \mathrm{mmol}, 93 \%$, meso: $d l=1.1: 1)$ after purification by flash column chromatography on silica-gel (hexane:ethyl acetate $=2: 1$ ).

Spectral data is in agreement with the reported literature. ${ }^{2 b}$

1H NMR (400 MHz, $\left.\mathrm{CDCl}_{3}, \mathrm{rt}\right): \delta 7.21-7.05$ (16H of meso and $\left.d l\right), 4.75$ (s, 2H of meso), 4.68 (s, 2H of $\left.d l\right)$, $2.71(\mathrm{~s}, 2 \mathrm{H}), 2.34(\mathrm{~s}, 6 \mathrm{H}$ of meso), $2.30(\mathrm{~s}, 6 \mathrm{H}$ of $d l), 2.03(\mathrm{~s}, 2 \mathrm{H})$. 
1,2-Di-o-tolylethane-1,2-diol (5c)<smiles>Cc1ccccc1C(O)C(O)c1ccccc1C</smiles>

According to the general procedures (reaction time $=1 \mathrm{~h}$ ), o-tolualdehyde $4 \mathrm{c}(26.4 \mathrm{mg}, 0.220 \mathrm{mmol}$ ) afforded $5 \mathrm{c}$ as a white solid $(24.3 \mathrm{mg}, 0.100 \mathrm{mmol}, 91 \%$, meso: $d l=1: 1.1)$ after purification by flash column chromatography on silica-gel (hexane:ethyl acetate $=2: 1$ ).

Spectral data is in agreement with the reported literature.2a

1H NMR $\left(400 \mathrm{MHz}, \mathrm{CDCl}_{3}, \mathrm{rt}\right): \delta 7.64-6.92(16 \mathrm{H}$ of meso and $d l), 5.22(\mathrm{~s}, 2 \mathrm{H}$ of meso), 5.00 (s, 2H of $d l)$, $2.85(\mathrm{~s}, 2 \mathrm{H}$ of $d l), 2.20$ (s, 6H of meso), 2.11 (s, 2H of meso), $1.68(\mathrm{~s}, 6 \mathrm{H}$ of $d l)$.

1,2-Bis(4-fluorophenyl)ethane-1,2-diol (5d)

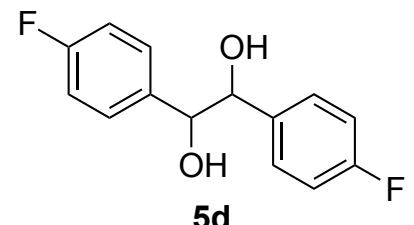

According to the general procedures (reaction time $=0.5 \mathrm{~h}$ ), 4-fluorobenzaldehyde $4 \mathbf{d}(27.3 \mathrm{mg}, 0.220$ mmol) afforded $\mathbf{5 d}$ as a white solid $(17.7 \mathrm{mg}, 0.0707 \mathrm{mmol}, 64 \%$, meso: $\mathrm{dl}=1.6: 1)$ after purification by flash column chromatography on silica-gel (hexane:ethyl acetate $=2: 1$ ).

Spectral data is in agreement with the reported literature.2a

1H NMR $\left(400 \mathrm{MHz}, \mathrm{CDCl}_{3}\right.$, rt): $\delta 7.18-6.90$ (16H of meso and $\left.d l\right), 4.83$ (s, 2H of meso), $4.64(\mathrm{~s}, 2 \mathrm{H}$ of $d l)$, 2.85 (s, $2 \mathrm{H}$ of $m e s o$ ), 2.25 (s, $2 \mathrm{H}$ of $d l)$.

1,2-Bis(3-methoxyphenyl)-1,2-ethanediol (5e)<smiles>COc1cccc(C(O)C(O)c2cccc(OC)c2)c1</smiles>

$5 e$

According to the general procedures (reaction time $=1 \mathrm{~h}$ ), 3-methoxybenzaldehyde $4 \mathrm{e}(30.0 \mathrm{mg}, 0.220$ $\mathrm{mmol}$ ) afforded $5 \mathrm{e}$ as a colorless oil $(25.6 \mathrm{mg}, 0.933 \mathrm{mmol}, 85 \%$, meso:dl $=1: 1)$ after purification by flash column chromatography on silica-gel (hexane:ethyl acetate $=2: 1$ ).

Spectral data is in agreement with the reported literature. ${ }^{2 c}$

1H NMR (400 MHz, $\mathrm{CDCl}_{3}$, rt): $\delta 7.24-6.72$ (16H of meso and $\left.d\right), 4.79$ (s, 2H of meso), 4.69 (s, 2H of $\left.d l\right)$, $3.75(\mathrm{~s}, 6 \mathrm{H}$ of $m e s o), 3.72(\mathrm{~s}, 6 \mathrm{H}$ of $d l), 2.79(\mathrm{~s}, 2 \mathrm{H}), 2.18(\mathrm{~s}, 2 \mathrm{H})$, 
2,3-Diphenylbutane-2,3-diol (5f)

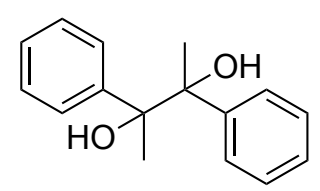

$5 \mathbf{f}$

According to the general procedures (reaction time $=1 \mathrm{~h}$ ), acetophenone $4 \mathrm{f}(26.4 \mathrm{mg}, 0.220 \mathrm{mmol}$ ) afforded $\mathbf{5 f}$ as a white solid ( $20.5 \mathrm{mg}, 0.0846 \mathrm{mmol}, 77 \%$, meso: $d l=1: 1.2)$ after purification by flash column chromatography on silica-gel (hexane:ethyl acetate $=2: 1$ ).

Spectral data is in agreement with the reported literature.2a

1H NMR (400 MHz, CDCl $3, \mathrm{rt}): \delta 7.25-7.19$ (20H of meso and $d l), 2.52$ (s, 2H of $d l), 2.23$ (s, $2 \mathrm{H}$ of meso), $1.59(\mathrm{~s}, 6 \mathrm{H}$ of meso), $1.52(\mathrm{~s}, 6 \mathrm{H}$ of $d l)$.

1,2-Diphenylethane-1,2-diol (5g)

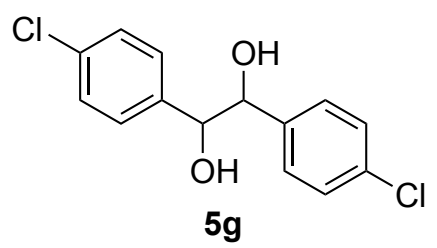

According to the general procedures (reaction time $=2 \mathrm{~h}$ ), 4-chlorobenzaldehyde $\mathbf{4 g}$ (30.9 $\mathrm{mg}, 0.220$ $\mathrm{mmol}$ ) afforded $\mathbf{5 g}$ as a white solid $(17.1 \mathrm{mg}, 0.0604 \mathrm{mmol}, 55 \%$, meso:dl $=1: 1.1)$ after purification by flash column chromatography on silica-gel (hexane:ethyl acetate $=2: 1$ ).

Spectral data is in agreement with the reported literature.2a

1H NMR (400 MHz, CDCl 3 , rt): $\delta 7.27-7.02$ (16H of meso and $d l), 4.84$ (s, 2H of meso), 4.63 (s, 2H of $d)$, $2.83(\mathrm{~s}, 2 \mathrm{H}$ of $d l) 2.27(\mathrm{~s}, 2 \mathrm{H}$ of $m e s o)$.

\section{1,1,2,2-Tetraphenylethane-1,2-diol (5h)}

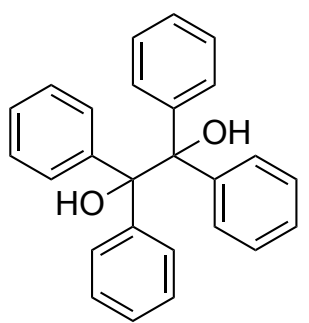

$5 \mathrm{~h}$

According to the general procedures (reaction time $=6 \mathrm{~h}$ ), benzophenone $4 \mathrm{~h}(23.3 \mathrm{mg}, 0.220 \mathrm{mmol}$ ) afforded $5 \mathrm{~h}$ as a white solid $(28.1 \mathrm{mg}, 0.0767 \mathrm{mmol}, 70 \%)$ after purification by flash column chromatography on silica-gel (hexane:ethyl acetate $=2: 1$ ) and recycling preparative HPLC.

Spectral data is in agreement with the reported literature.2a

1H NMR (400 MHz, $\left.\mathrm{CDCl}_{3}, \mathrm{rt}\right): \delta 7.33-7.16(12 \mathrm{H}), 3.04(\mathrm{~s}, 2 \mathrm{H})$. 
1,2-Bis(4-butylphenyl)ethane-1,2-diol (5i)

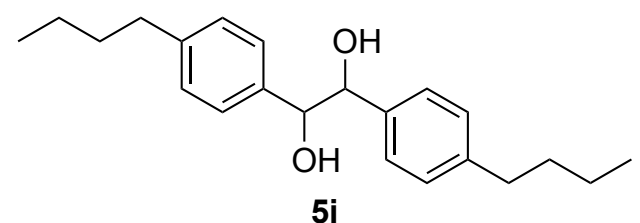

1. with catalyst $\mathbf{2 a} \cdot \mathbf{3 a}$ in $\mathrm{H}_{2} \mathrm{O}$

According to the general procedures (reaction time $=1 \mathrm{~h}$ ), 4-hexylbenzaldehyde $4 \mathbf{i}(35.7 \mathrm{mg}, 0.220 \mathrm{mmol}$ ) afforded $\mathbf{5 i}$ (10\% NMR yield). The yield was determined by the ${ }^{1} \mathrm{H}$ NMR spectrum with dimethyl sulfone as an internal standard.

2. with catalyst $\mathbf{3 a}$ in DMF

A mixture of 4-hexylbenzaldehyde $4 \mathbf{i}(35.7 \mathrm{mg}, 0.220 \mathrm{mmol})$, triethylamine $(44.5 \mathrm{mg}, 0.440 \mathrm{mmol})$ and $3 a$ $(1.35 \mathrm{mg}, 2.20 \mu \mathrm{mol})$ in DMF $(2 \mathrm{~mL})$ was stirred $(500 \mathrm{rpm})$ for $1 \mathrm{~h}$ at room temperature under visible light irradiation, cooling by a fan. Then, water was added, and the resulting mixture was extracted with $\mathrm{Et}_{2} \mathrm{O}$. The organic layer was dried over $\mathrm{Na}_{2} \mathrm{SO}_{4}$, and evaporated. The yield was determined by the ${ }^{1} \mathrm{H}$ NMR spectrum with dimethyl sulfone as an internal standard (63\% NMR yield), and then purification was performed by column chromatography on silica-gel (hexane:ethyl acetate $=2: 1$ ) to give $\mathbf{5} \mathbf{i}$ as a white solid (21.3 mg, $0.0652 \mathrm{mmol}, 59 \%)$.

1H NMR $\left(400 \mathrm{MHz}, \mathrm{CDCl}_{3}\right.$, rt): $\delta 7.22-7.05(16 \mathrm{H}$ of meso and $d l), 4.73(\mathrm{~s}, 2 \mathrm{H}), 4.67(\mathrm{~s}, 2 \mathrm{H}), 2.82(\mathrm{~s}, 2 \mathrm{H})$, $2.62-2.54(\mathrm{~m}, 8 \mathrm{H}$ of meso and $d l), 2.13(\mathrm{~s}, 2 \mathrm{H}), 1.61-0.89(28 \mathrm{H}$ of meso and $d l)$.

${ }^{13} \mathrm{C}$ NMR $\left(100 \mathrm{MHz}, \mathrm{CDCl}_{3}\right.$, rt): $\delta 143.0,142.7,137.5,137.4,128.5,128.3,127.2,126.9,79.0,78.3,35.5$, $35.4,33.69,33.66,22.44,22.38,14.05(2 \mathrm{C})$.

HRMS (ESI-TOF) calcd $\mathrm{m} / \mathrm{z}$ for $\left[\mathrm{C}_{22} \mathrm{H}_{30} \mathrm{O}_{2}+\mathrm{Na}\right]^{+} 349.2138$ found 349.2137 .

1,2-Bis(4-hexylphenyl)ethane-1,2-diol (5j)

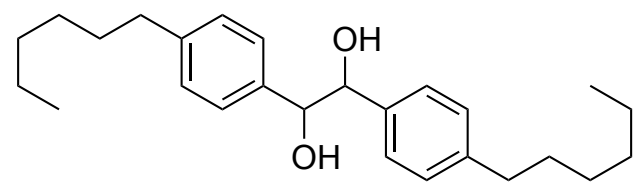

$5 \mathbf{j}$

1. with catalyst $\mathbf{2 a} \cdot \mathbf{3 a}$ in $\mathrm{H}_{2} \mathrm{O}$

According to the general procedures (reaction time $=1 \mathrm{~h})$, 4-hexylbenzaldehyde $4 \mathbf{j}(41.9 \mathrm{mg}, 0.220 \mathrm{mmol}$ ) afforded $5 \mathbf{j}$ (5\% NMR yield). The yield was determined by the ${ }^{1} \mathrm{H}$ NMR spectrum with dimethyl sulfone as an internal standard.

2. with catalyst $\mathbf{3 a}$ in DMF

A mixture of 4-hexylbenzaldehyde $4 \mathbf{j}(41.9 \mathrm{mg}, 0.220 \mathrm{mmol})$, triethylamine $(44.5 \mathrm{mg}, 0.440 \mathrm{mmol})$ and $3 \mathrm{a}$ $(1.35 \mathrm{mg}, 2.20 \mu \mathrm{mol})$ in DMF $(2 \mathrm{~mL})$ was stirred $(500 \mathrm{rpm})$ for $1 \mathrm{~h}$ at room temperature under visible light irradiation, cooling by a fan. Then, water was added, and the resulting mixture was extracted with $\mathrm{Et}_{2} \mathrm{O}$. The organic layer was dried over $\mathrm{Na}_{2} \mathrm{SO}_{4}$, and evaporated. The yield was determined by the ${ }^{1} \mathrm{H} \mathrm{NMR}$ spectrum with dimethyl sulfone as an internal standard (57\% NMR yield), and then purification was 
performed by column chromatography on silica-gel (hexane:ethyl acetate $=2: 1$ ) and recycling preparative HPLC to obtain $5 \mathrm{j}$ as a white solid (23.7 $\mathrm{mg}, 0.0619 \mathrm{mmol}, 56 \%)$.

1H NMR (400 MHz, $\left.\mathrm{CDCl}_{3}, \mathrm{rt}\right): \delta 7.23-7.05$ (16H of meso and $\left.d\right), 4.75(\mathrm{~s}, 2 \mathrm{H}), 4.69(\mathrm{~s}, 2 \mathrm{H}), 2.61-2.53(\mathrm{~m}$, $8 \mathrm{H}$ of meso and $d l), 2.03$ (brs, $4 \mathrm{H}$ of meso and $d l), 1.61-0.86$ (44H of meso and $d l)$.

${ }^{13} \mathrm{C}$ NMR $\left(100 \mathrm{MHz}, \mathrm{CDCl}_{3}\right.$, rt): $\delta 143.1,142.7,137.42,137.39,128.5,128.3,127.2,126.9,79.0,78.3$, $35.8,35.7,31.9(2 \mathrm{C}), 31.50,31.45,29.1,29.0,22.8(2 \mathrm{C}), 14.2(2 \mathrm{C})$.

HRMS (ESI-TOF) calcd $\mathrm{m} / \mathrm{z}$ for $\left[\mathrm{C}_{26} \mathrm{H}_{38} \mathrm{O}_{2}+\mathrm{Na}\right]^{+} 405.2764$ found 405.2766 .

\section{Procedures for HAT Reaction and Characterization}<smiles>CC(C)N(C(=O)c1ccccc1I)C(C)C</smiles>

6

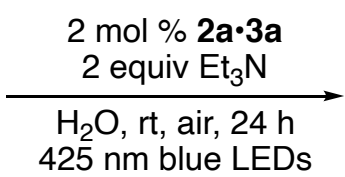

$425 \mathrm{~nm}$ blue LEDs

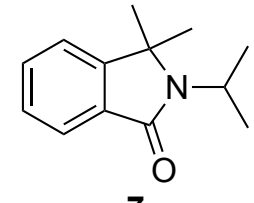

7

A $4 \mathrm{~mL}$ sample bottle was charged with 2-iodo- $N, N$-diisopropylbenzamide 6 (54.6 mg, $0.165 \mathrm{mmol})$, triethylamine (33.4 mg, $0.330 \mathrm{mmol}$ ), and a $\mathrm{H}_{2} \mathrm{O}$ solution of $\mathbf{2 a} \cdot \mathbf{3 a}$ (ca. $1.1 \mathrm{mM}, 3 \mathrm{~mL}$ ), and then it was placed at a distance of $1 \mathrm{~cm}$ away from blue LED lamps $(\lambda=425 \mathrm{~nm})$. The mixture was irradiated with stirring $(500 \mathrm{rpm})$ and cooling by a fan for $24 \mathrm{~h}$. Then, water was added, and the resulting mixture was extracted with $\mathrm{Et}_{2} \mathrm{O}$. The organic layer was dried over $\mathrm{Na}_{2} \mathrm{SO}_{4}$, and evaporated. The desired product 7 was obtained as a white solid (15.8 $\mathrm{mg}, 0.0778 \mathrm{mmol}, 47 \%$ ) after purification by flash column chromatography on silica-gel (hexane:ethyl acetate $=2: 1$ ).

Spectral data is in agreement with the reported literature. ${ }^{2 \mathrm{~d}}$

1H NMR (400 MHz, $\mathrm{CDCl}_{3}$, rt): $\delta 7.77(\mathrm{~d}, J=7.5 \mathrm{~Hz}, 1 \mathrm{H}), 7.50$ (t, $\left.J=7.4 \mathrm{~Hz}, 1 \mathrm{H}\right), 7.40(\mathrm{t}, J=7.4 \mathrm{~Hz}, 1 \mathrm{H})$, $7.34(\mathrm{~d}, J=7.5 \mathrm{~Hz}, 1 \mathrm{H}), 3.65(\mathrm{~m}, 1 \mathrm{H}), 1.56(\mathrm{~s}, J=6.9 \mathrm{~Hz}, 6 \mathrm{H}), 1.48(\mathrm{~s}, 6 \mathrm{H})$.

\section{Procedures for Trifluoromethylation and Characterization}

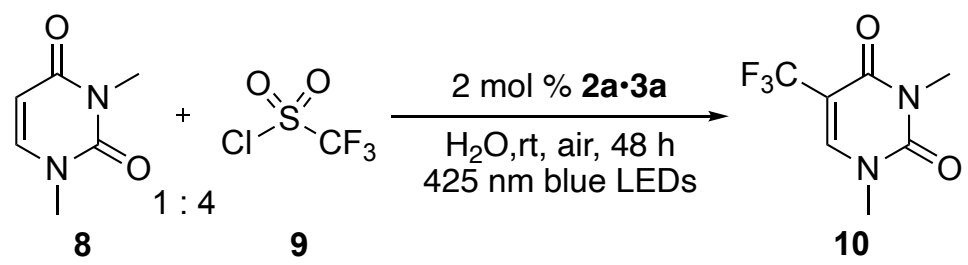

A $4 \mathrm{~mL}$ sample bottle was charged with 1,3-dimethyluracil 8 ( $23.1 \mathrm{mg}, 0.165 \mathrm{mmol})$, triflyl chloride 9 (69.5 $\mu \mathrm{L}, 0.660 \mathrm{mmol}$ ), and $\mathrm{a} \mathrm{H}_{2} \mathrm{O}$ solution of $2 \mathrm{a} \cdot 3 \mathrm{a}$ (ca. $1.1 \mathrm{mM}, 3 \mathrm{~mL}$ ), and then it was placed at a distance of $1 \mathrm{~cm}$ away from blue LED lamps $(\lambda=425 \mathrm{~nm})$. The mixture was irradiated with stirring $(500 \mathrm{rpm})$ and cooling by a fan for $48 \mathrm{~h}$. Then, water was added, and the resulting mixture was extracted with $\mathrm{Et}_{2} \mathrm{O}$. The organic layer was dried over $\mathrm{Na}_{2} \mathrm{SO}_{4}$, and evaporated. The desired product 10 was obtained as a white solid (22.4 mg, $0.108 \mathrm{mmol}, 65 \%)$ after purification by flash column chromatography on silica-gel $\left(\mathrm{Et}_{2} \mathrm{O}\right)$. Spectral data is in agreement with the reported literature. ${ }^{2 e}$

1H NMR (400 MHz, $\left.\mathrm{CDCl}_{3}, \mathrm{rt}\right): \delta 7.66(\mathrm{~s}, 1 \mathrm{H}), 3.49(\mathrm{~s}, 3 \mathrm{H}), 3.37(\mathrm{~s}, 3 \mathrm{H})$. 
19F NMR (376 MHz, $\mathrm{CDCl}_{3}$, rt): $\delta-64.8$ (s).

\section{Recycling Experiments}

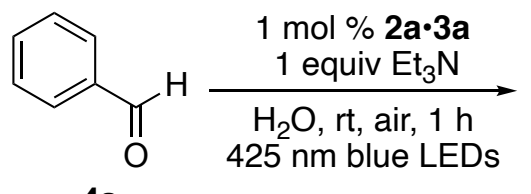

$4 a$<smiles>OC(c1ccccc1)C(O)c1ccccc1</smiles>

$5 a$

A test tube was charged with benzaldehyde $4 \mathrm{a}(0.110 \mathrm{mmol})$, triethylamine $(0.110 \mathrm{mml})$, and a $\mathrm{H}_{2} \mathrm{O}$ solution of $2 \mathrm{a} \cdot 3 \mathbf{a}$ (ca. $1.1 \mathrm{mM}, 1 \mathrm{~mL}$ ), and then it was placed at a distance of $1 \mathrm{~cm}$ away from blue LED lamps $(\lambda=$ $425 \mathrm{~nm})$. The mixture was irradiated with stirring ( $500 \mathrm{rpm})$ and cooling by a fan for $1 \mathrm{~h}$. Then, $\mathrm{Et}_{2} \mathrm{O}$ was added and the mixture was stirred vigorously $(1000 \mathrm{rpm})$ for $1 \mathrm{~min}$. The biphasic system was centrifuged for $5 \mathrm{~min}$, and the organic layer was separated. These extraction protocols were carried out for three times. The organic layer was removed under reduced pressure, and the crude product was purified by flash column chromatography on silica-gel (hexane:ethyl acetate $=2: 1$ ) to afford $5 \mathbf{a}$.

The substrates were added again to the aqueous layer containing the catalyst, and the same procedures were conducted. The photocatalytic reaction was repeated three cycles.

first run

benzaldehyde $(11.7 \mathrm{mg}, 0.110 \mathrm{mmol})$ and triethylamine $(11.1 \mathrm{mg}, 0.110 \mathrm{mmol})$ afforded $\mathbf{5 a}(10.2 \mathrm{mg}$, $0.0476 \mathrm{mmol}, 86 \%$ ) as a white solid after purification.

second run

benzaldehyde $(11.7 \mathrm{mg}, 0.110 \mathrm{mmol})$ and triethylamine $(11.1 \mathrm{mg}, 0.110 \mathrm{mmol})$ afforded $5 \mathrm{a}(10.7 \mathrm{mg}, 0.499$ mmol, $91 \%$ ) as a white solid after purification.

third run

benzaldehyde $(11.8 \mathrm{mg}, 0.111 \mathrm{mmol})$ and triethylamine $(11.0 \mathrm{mg}, 0.109 \mathrm{mmol})$ afforded $5 \mathrm{a}(11.0 \mathrm{mg}$, $0.0513 \mathrm{mmol}, 92 \%)$ as a white solid after purification.
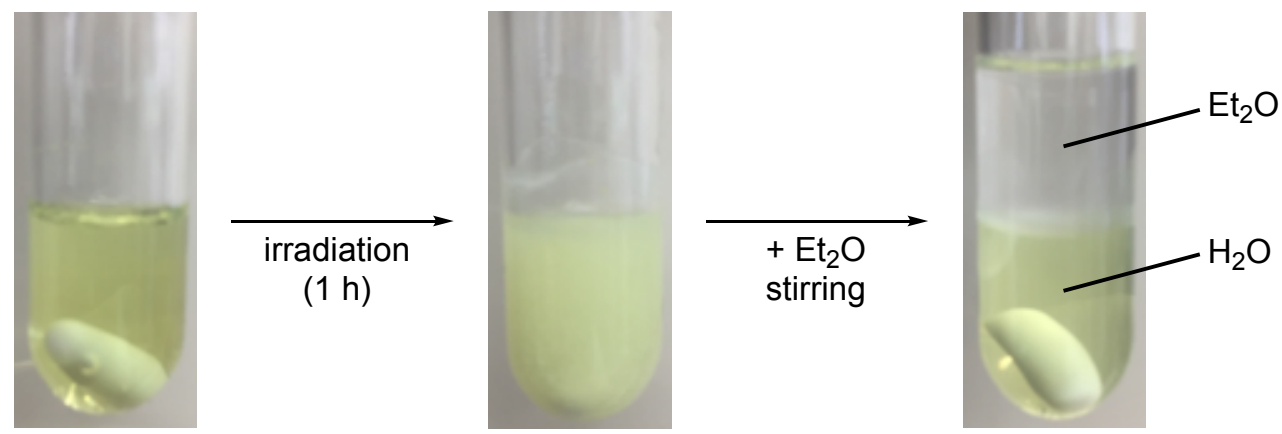


\section{Competition Experiments}

Competition experiment of $\mathbf{4 b}$ and $\mathbf{4} \mathbf{i}$ with capsule-free catalyst $\mathbf{3} \mathbf{a}$ in DMF<smiles>Cc1ccc(C=O)cc1</smiles><smiles>CCCCc1ccc(C=O)cc1</smiles>

$2 \mathrm{~mol} \% \mathbf{3 a}$

4 equiv $\mathrm{Et}_{3} \mathrm{~N}$

DMF, rt, air, 30 min

$425 \mathrm{~nm}$ blue LEDs<smiles>Cc1ccc(C(O)C(O)c2ccc(C)cc2)cc1</smiles>

$5 b$<smiles>CCCCc1ccc(C(O)C(O)c2ccc(C)cc2)cc1</smiles>

$11 \mathrm{bi}$

$4 \mathrm{i}$<smiles>CCCCc1ccc(C(O)C(O)c2ccc(CCCC)cc2)cc1</smiles>

$5 i$

A $4 \mathrm{~mL}$ sample bottle was charged with $\mathbf{4 b}(13.2 \mathrm{mg}, 0.110 \mathrm{mmol}), 4 \mathbf{i}(17.8 \mathrm{mg}, 0.110 \mathrm{mmol})$, triethylamine (44.5 mg, $0.440 \mathrm{mmol}), 3 a(1.35 \mathrm{mg}, 2.20 \mu \mathrm{mol})$, and DMF ( $2 \mathrm{~mL})$, and then it was placed at a distance of $1 \mathrm{~cm}$ away from blue LED lamps $(\lambda=425 \mathrm{~nm})$. The mixture was irradiated with stirring $(500 \mathrm{rpm})$ and cooling by a fan for $30 \mathrm{~min}$. Then, water $(15 \mathrm{~mL})$ was added, and the resulting mixture was extracted with $\mathrm{Et}_{2} \mathrm{O}(15 \mathrm{~mL} \times 3)$. The organic layer was washed with $\mathrm{H}_{2} \mathrm{O}(15 \mathrm{~mL} \times 3)$, dried over $\mathrm{Na}_{2} \mathrm{SO}_{4}$, and evaporated. The residue was dried under vacuum in ice bath for $5 \mathrm{~min}$. The conversion of substrates was determined by the ${ }^{1} \mathrm{H}$ NMR spectrum using dimethyl sulfone as an internal standard (conversion values (\%) of $4 \mathbf{b}$ and $4 \mathbf{i}$ are 81 and 79, respectively).

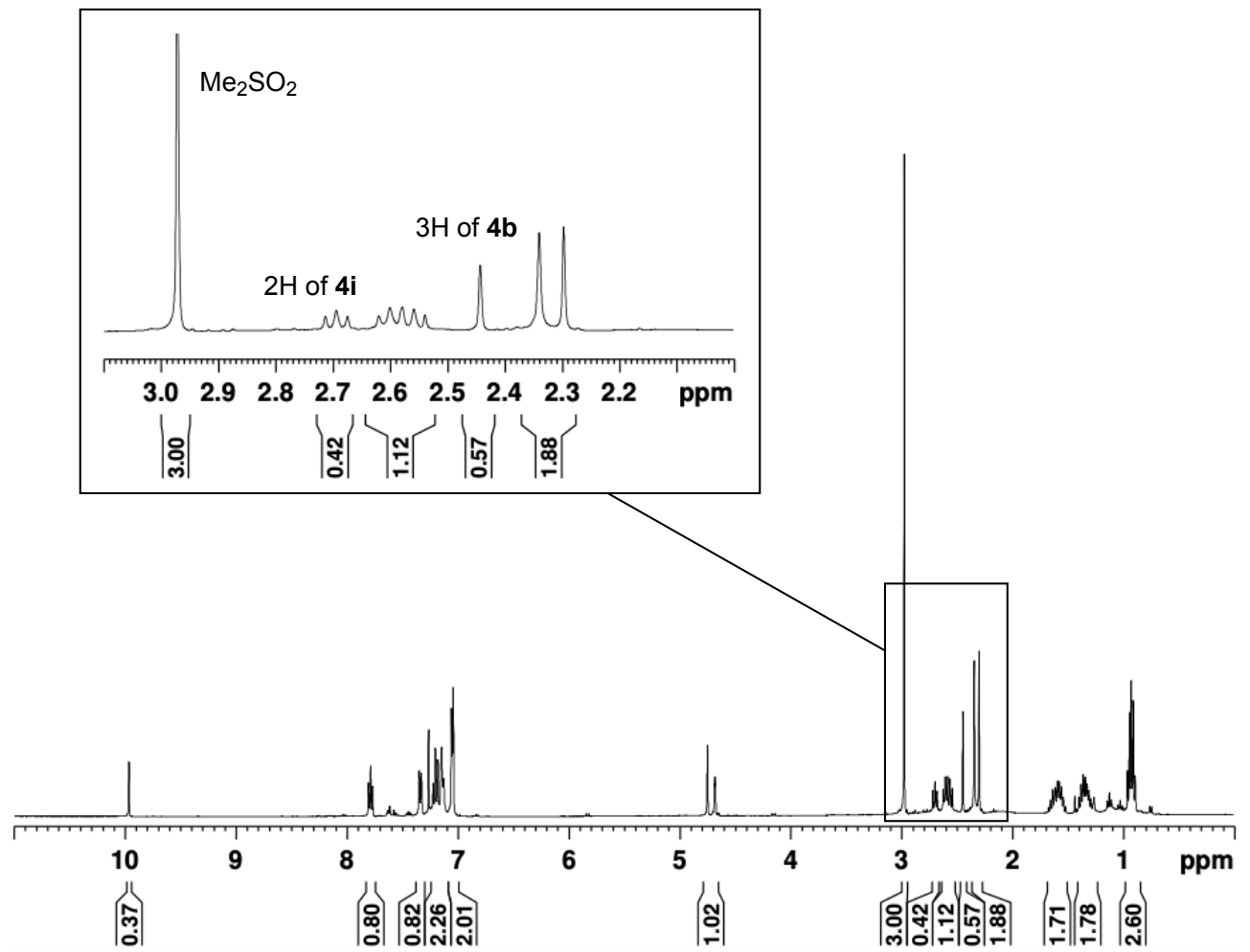

Figure S12. ${ }^{1 H}$ NMR spectrum of after the reaction with $\mathbf{3 a}$ in DMF $\left(400 \mathrm{MHz}, \mathrm{CDCl}_{3}, \mathrm{rt}\right)$. 


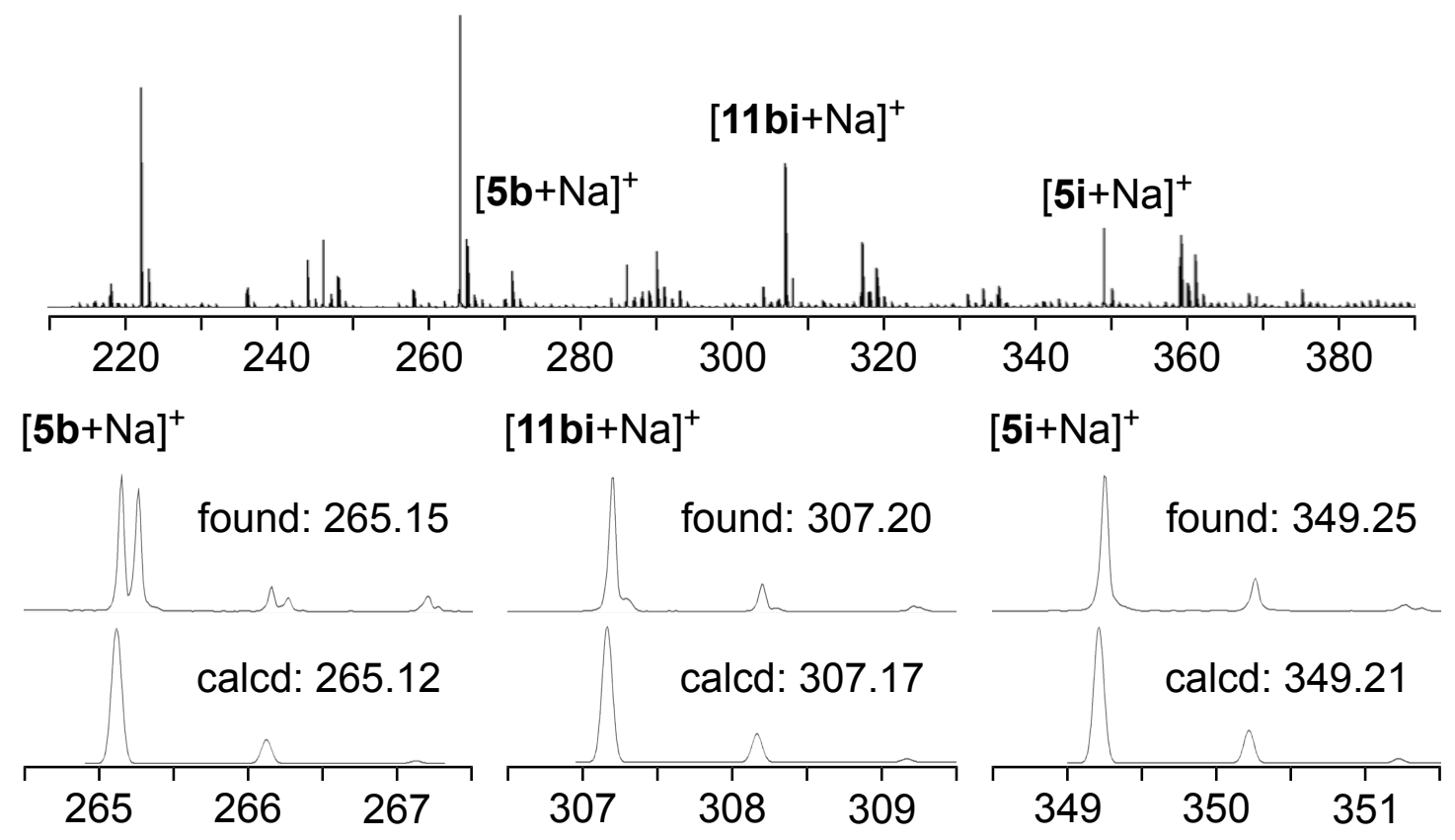

Figure S13. ESI-TOF MS of a reaction mixture. 
Competition experiment between $\mathbf{4} \mathbf{b}$ and $\mathbf{4} \mathbf{i}$ with supramolecular catalyst $\mathbf{2 a} \cdot \mathbf{3} \mathbf{a}$ in $\mathrm{H}_{2} \mathrm{O}$

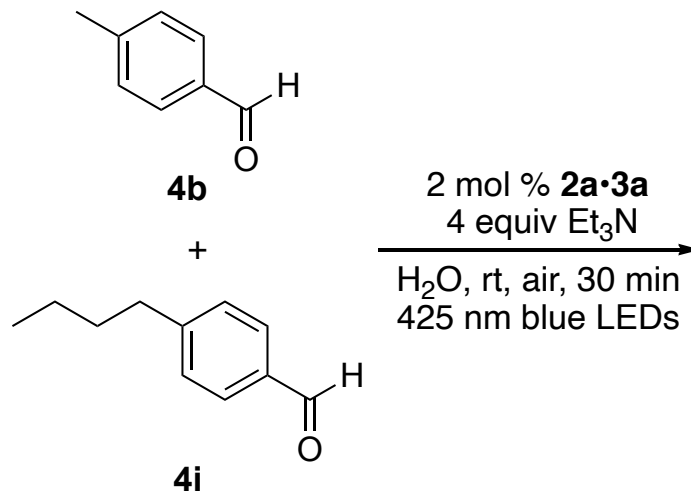<smiles>Cc1ccc(C(O)C(O)c2ccc(C)cc2)cc1</smiles>

$5 \mathbf{b}$<smiles>CCCCc1ccc(C(O)C(O)c2ccc(C)cc2)cc1</smiles>

$11 \mathrm{bi}$<smiles>CCCCc1ccc(C(O)C(O)c2ccc(CCCC)cc2)cc1</smiles>

$5 \mathbf{i}$

A $4 \mathrm{~mL}$ sample bottle was charged with $4 \mathbf{b}(13.2 \mathrm{mg}, 0.110 \mathrm{mmol}), 4 \mathbf{i}(17.8 \mathrm{mg}, 0.110 \mathrm{mmol})$, triethylamine (44.5 mg, $0.440 \mathrm{mmol}$ ), and $\mathrm{a} \mathrm{H}_{2} \mathrm{O}$ solution of $2 \mathrm{a} \cdot 3 \mathrm{a}$ (ca $1.1 \mathrm{mg}, 2 \mathrm{~mL}$ ), and then it was placed at a distance of $1 \mathrm{~cm}$ away from blue LED lamps $(\lambda=425 \mathrm{~nm})$. The mixture was irradiated with stirring (500 rpm) and cooling by a fan for $30 \mathrm{~min}$. Then, water $(15 \mathrm{~mL})$ was added, and the resulting mixture was extracted with $\mathrm{Et}_{2} \mathrm{O}(15 \mathrm{~mL} \times 3)$. The organic layer was washed with $\mathrm{H}_{2} \mathrm{O}(15 \mathrm{~mL} \times 3)$, dried over $\mathrm{Na}_{2} \mathrm{SO}_{4}$, and evaporated. The residue was dried under vacuum in ice bath for $5 \mathrm{~min}$. The conversion of substrates was determined by the ${ }^{1 H}$ NMR spectrum with dimethyl sulfone as an internal standard (conversion values (\%) of $\mathbf{4 b}$ and $4 \mathbf{i}$ are 84 and 33 , respectively).

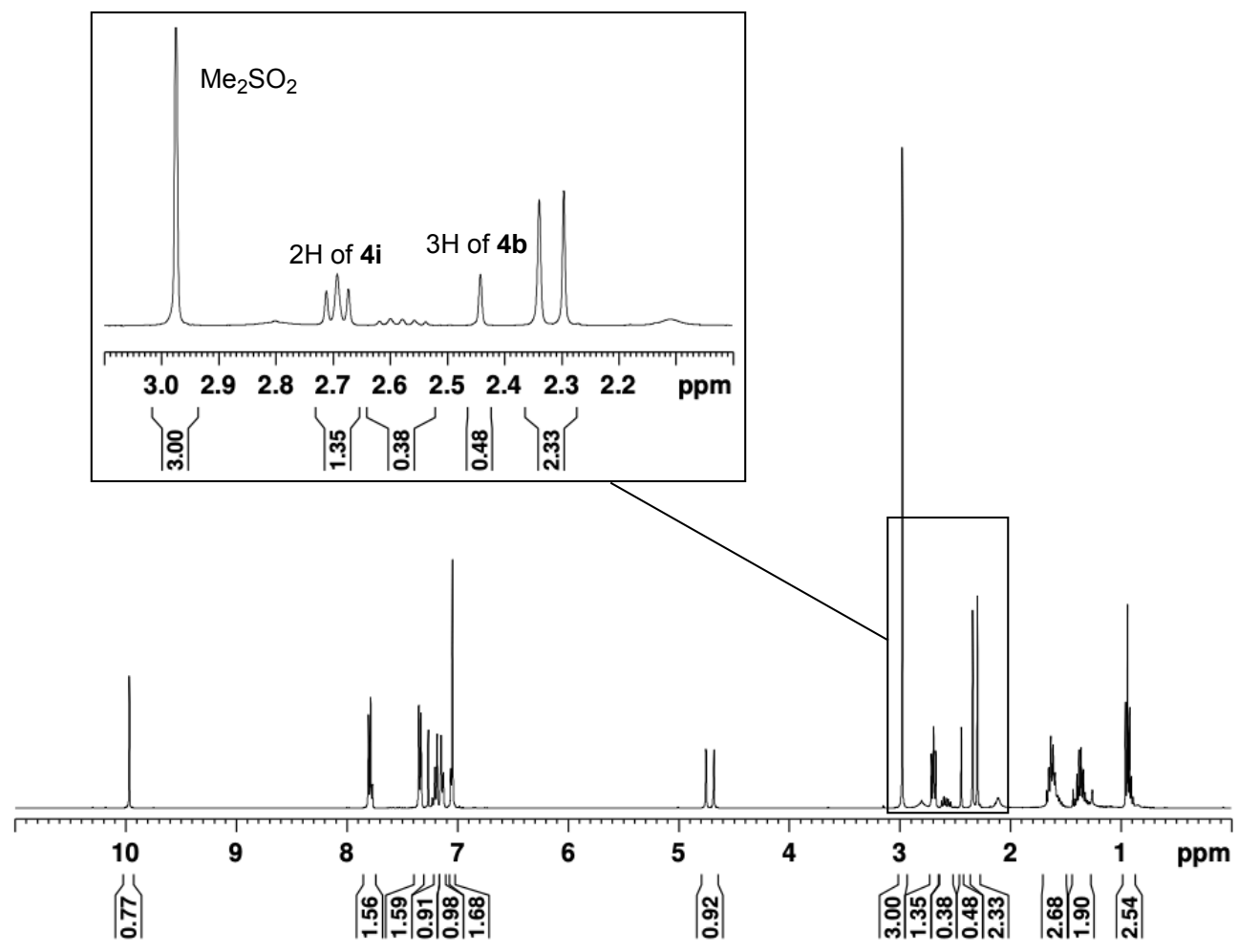

Figure S14. ${ }^{1} \mathrm{H}$ NMR spectrum of after the reaction with $\mathbf{2 a} \cdot \mathbf{3 a}$ in $\mathrm{H}_{2} \mathrm{O}\left(400 \mathrm{MHz}, \mathrm{CDCl}_{3}, \mathrm{rt}\right)$. 


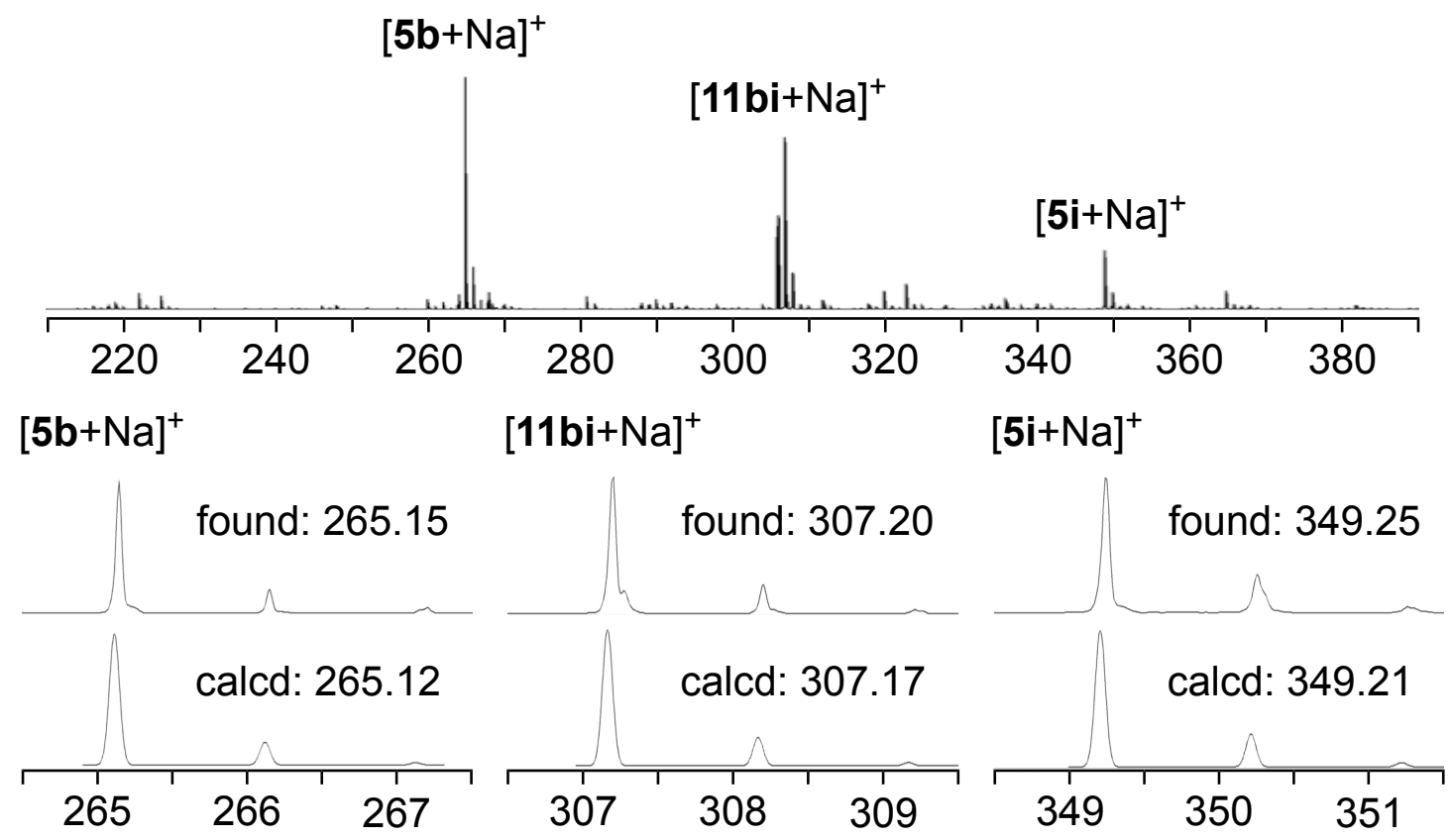

Figure S15. ESI-TOF MS of a reaction mixture.

Solubility of $\mathbf{4 b}$ and $\mathbf{4} \mathbf{i}$ to $\mathrm{D}_{2} \mathrm{O}$

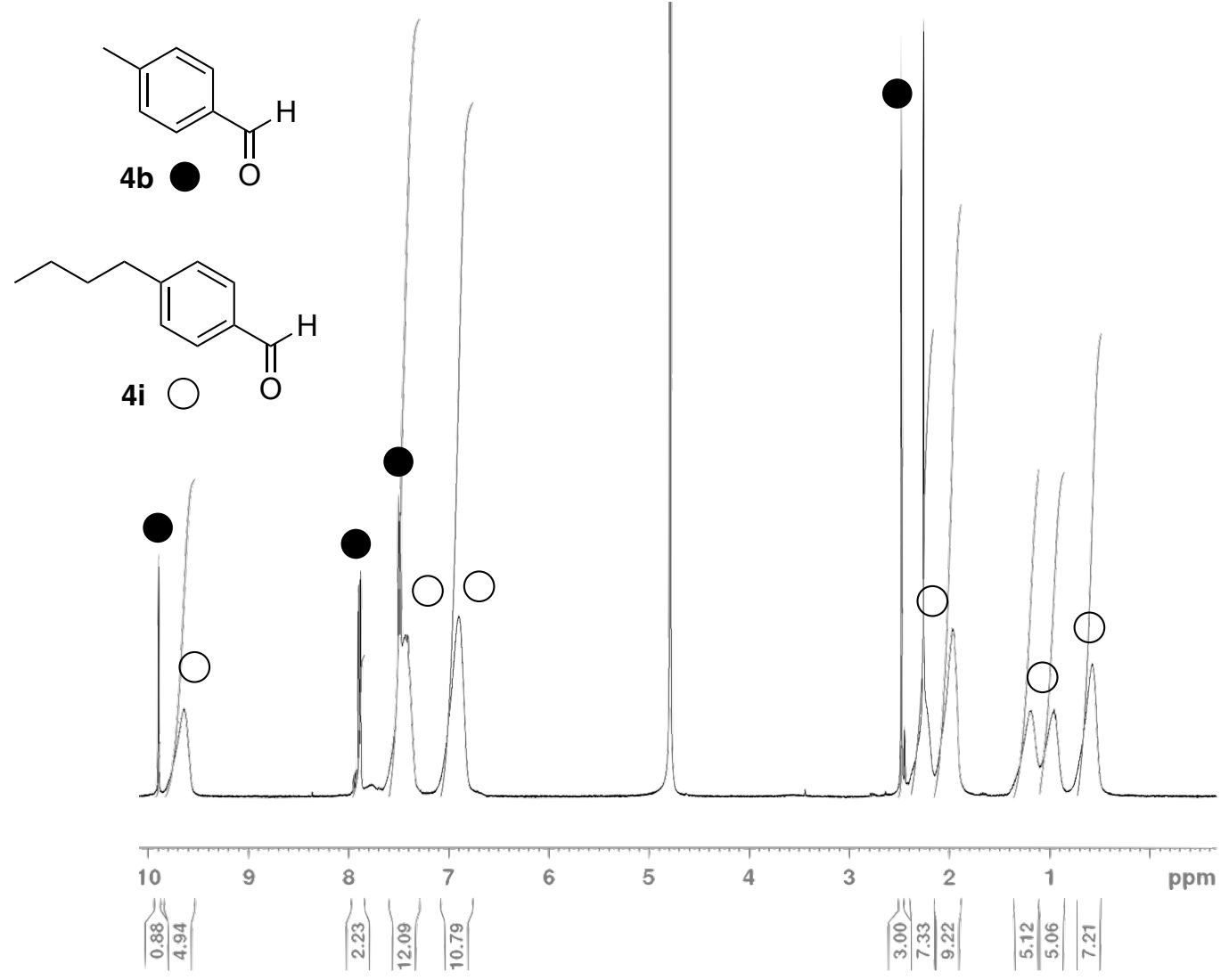

Figure S16. ${ }^{1} \mathrm{H}$ NMR of a mixture of $4 \mathbf{b}$ and $4 \mathbf{i}\left(400 \mathrm{MHz}, \mathrm{D}_{2} \mathrm{O}, \mathrm{rt}\right)$. 


\section{Luminescence Quenching Experiments}

$1(1 \mu \mathrm{mol})$ and $\mathbf{3 a}(1 \mu \mathrm{mol})$ afforded $0.07 \mathrm{mM}$ of a $\mathrm{H}_{2} \mathrm{O}$ solution of $\mathbf{2} \mathbf{a} \cdot \mathbf{3 a}$, and this solution was used for luminescence quenching experiments.
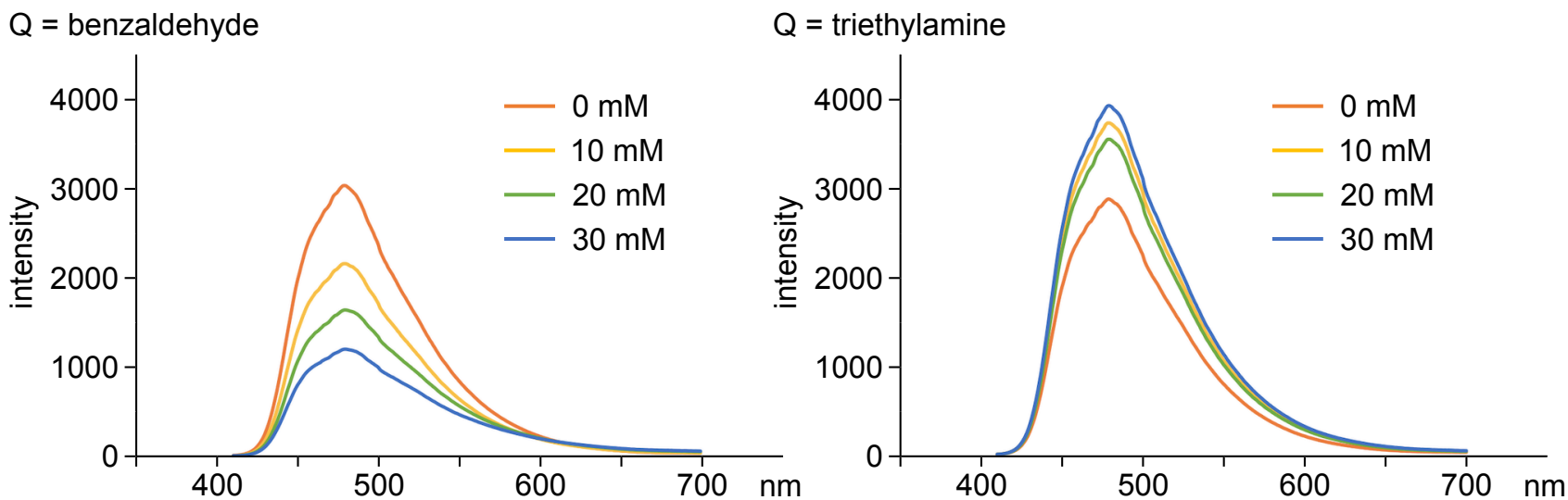

Figure S17. Changes of luminescence spectra of $\mathbf{2 a} \cdot \mathbf{3 a}$ by addition of substrates.

\section{References}

1 (a) Okazawa, Y.; Kondo, K.; Akita, M.; Yoshizawa, M. Well-Defined Aqueous Nanoassemblies from Amphiphilic meta-Terphenyls and Their Guest Incorporation. Chem. Sci. 2015, 6, 5059. (b) Pearson, R. M.; Lim, C.-H.; McCarthy, B. G.; Musgrave, C. B.; Miyake, G. M. Organocatalyzed Atom Transfer Radical Polymerization Using N-Aryl Phenoxazines as Photoredox Catalysts. J. Am. Chem. Soc. 2016, 138, 11399.

(c) Okazawa, Y.; Kondo, K.; Akita, M.; Yoshizawa, M. Polyaromatic Nanocapsules Displaying AggregationInduced Enhanced Emissions in Water. J. Am. Chem. Soc. 2015, 137, 98.

2 (a) Nakajima, M.; Fava, E.; Loescher, S.; Jiang, Z.; Rueping, M. Photoredox-Catalyzed Reductive Coupling of Aldehydes, Ketones, and Imines with Visible Light. Angew. Chem. Int. Ed. 2015, 54, 8828. (b) Okamoto, S.; Kojiyama, K.; Tsujioka, H.; Sudo, A. Metal-Free Reductive Coupling of $\mathrm{C}=\mathrm{O}$ and $\mathrm{C}=\mathrm{N}$ Bonds Driven by Visible Light: Use of Perylene as a Simple Photoredox Catalyst. Chem. Commun. 2016, 52, 11339. (c) Sotto, N.; Billamboz, M.; Chevrin-Villette, C.; Len, C. Selective Pinacol Coupling on Regeneratable Supported Acids in Sole Water. J. Org. Chem. 2015, 80, 6375. (d) Chen, J.-Q.; Wei, Y.-L.; Xu, G.-Q.; Liang, Y.-M.; Xu, P.-F. Intramolecular 1,5-H Transfer Reaction of Aryl lodides through VisibleLight Photoredox Catalysis: A Concise Method for the Synthesis of Natural Product Scaffolds. Chem. Commun. 2016, 52, 6455. (e) Nagib, D. A.; MacMillan, D. W. C. Trifluoromethylation of Arenes and Heteroarenes by Means of Photoredox Catalysis. Nature 2011, 480, 224.

3 Mahmood, Z.; Zhao, J. Thiol-Activatable Triplet-Triplet Annihilation Upconversion with MaleimidePerylene as the Caged Triplet Acceptor/Emitter. J. Org. Chem. 2016, 81, 587.

4 Noto, N.; Koike, T.; Akita, M. Visible-Light-Triggered Monofluoromethylation of Alkenes by Strongly Reducing 1,4-Bis(diphenylamino)naphthalene Photoredox Catalysis. ACS Catal. 2019, 9, 4382. 
NMR Spectra

${ }^{1} \mathrm{H}$ NMR (400 MHz, $\mathrm{CDCl}_{3}$, rt)
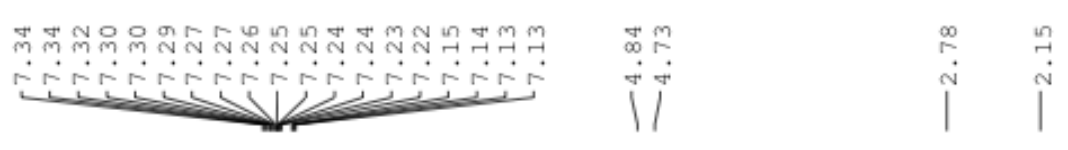<smiles>OC(c1ccccc1)C(O)c1ccccc1</smiles>

$5 a$

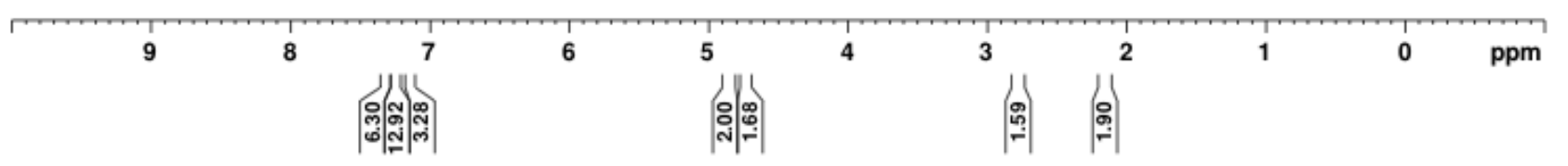

${ }^{1} \mathrm{H}$ NMR (400 MHz, $\mathrm{CDCl}_{3}$, rt)
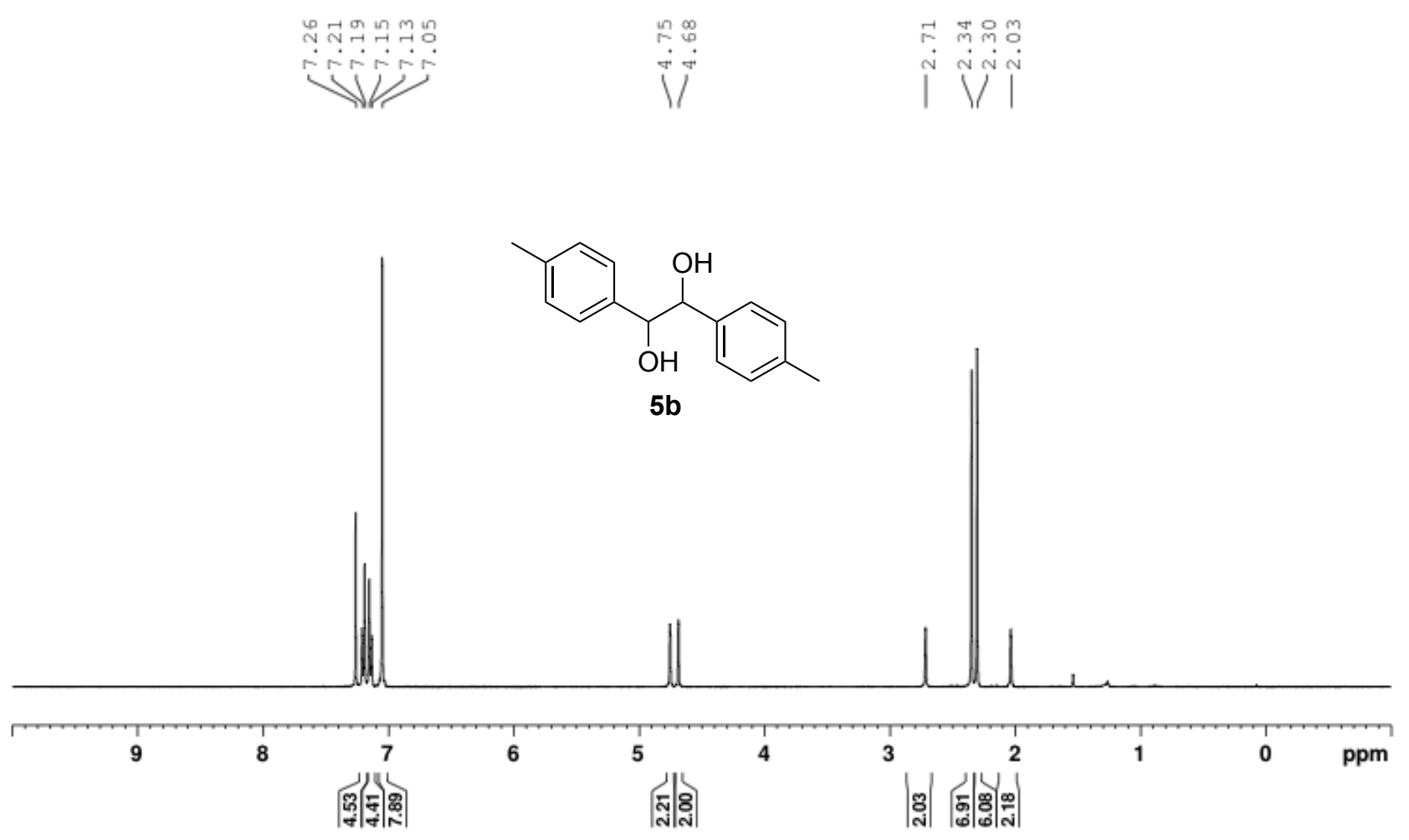

S22 
${ }^{1} \mathrm{H}$ NMR $\left(400 \mathrm{MHz}, \mathrm{CDCl}_{3}, \mathrm{rt}\right)$

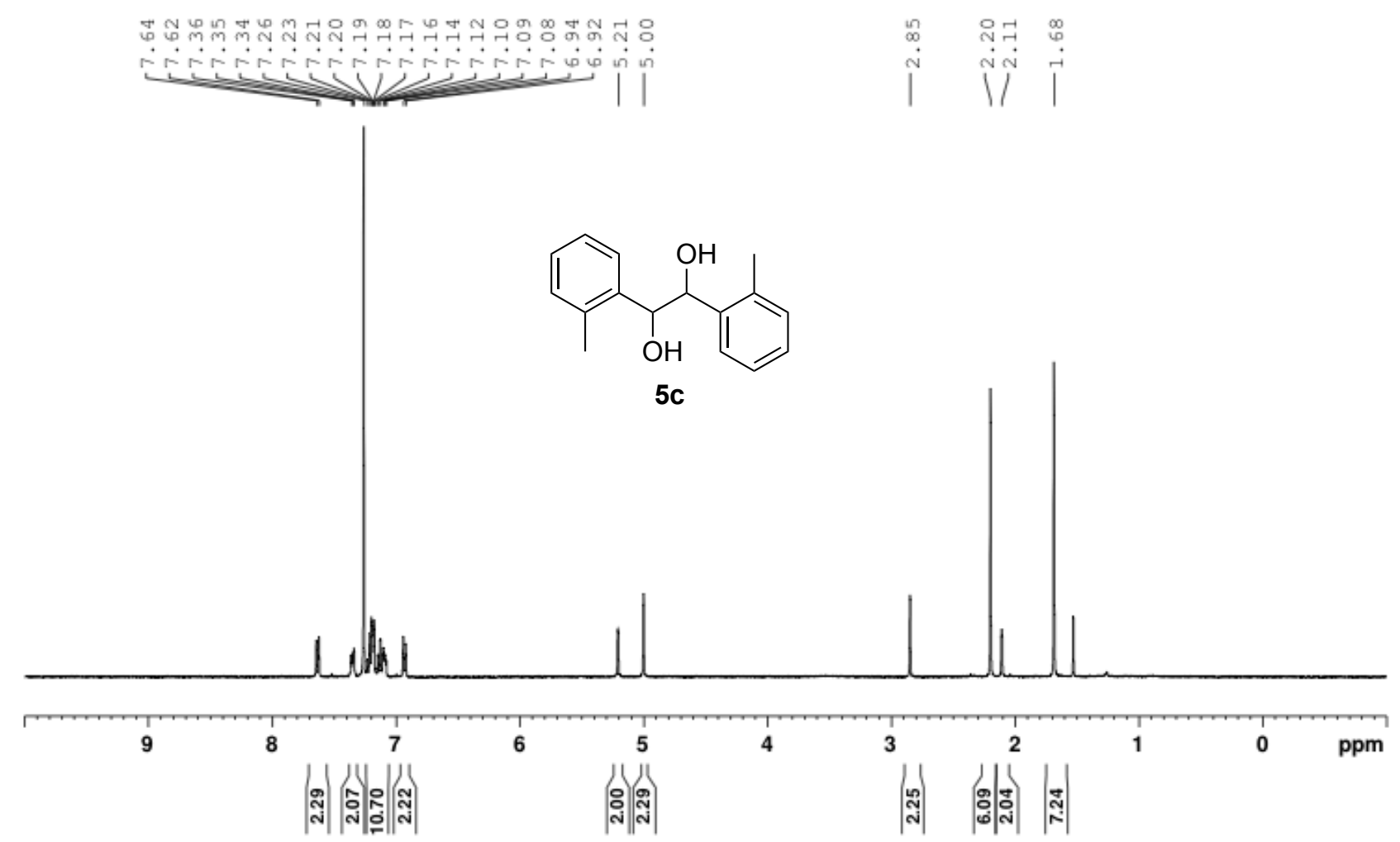

${ }^{1} \mathrm{H}$ NMR $\left(400 \mathrm{MHz}, \mathrm{CDCl}_{3}, \mathrm{rt}\right)$
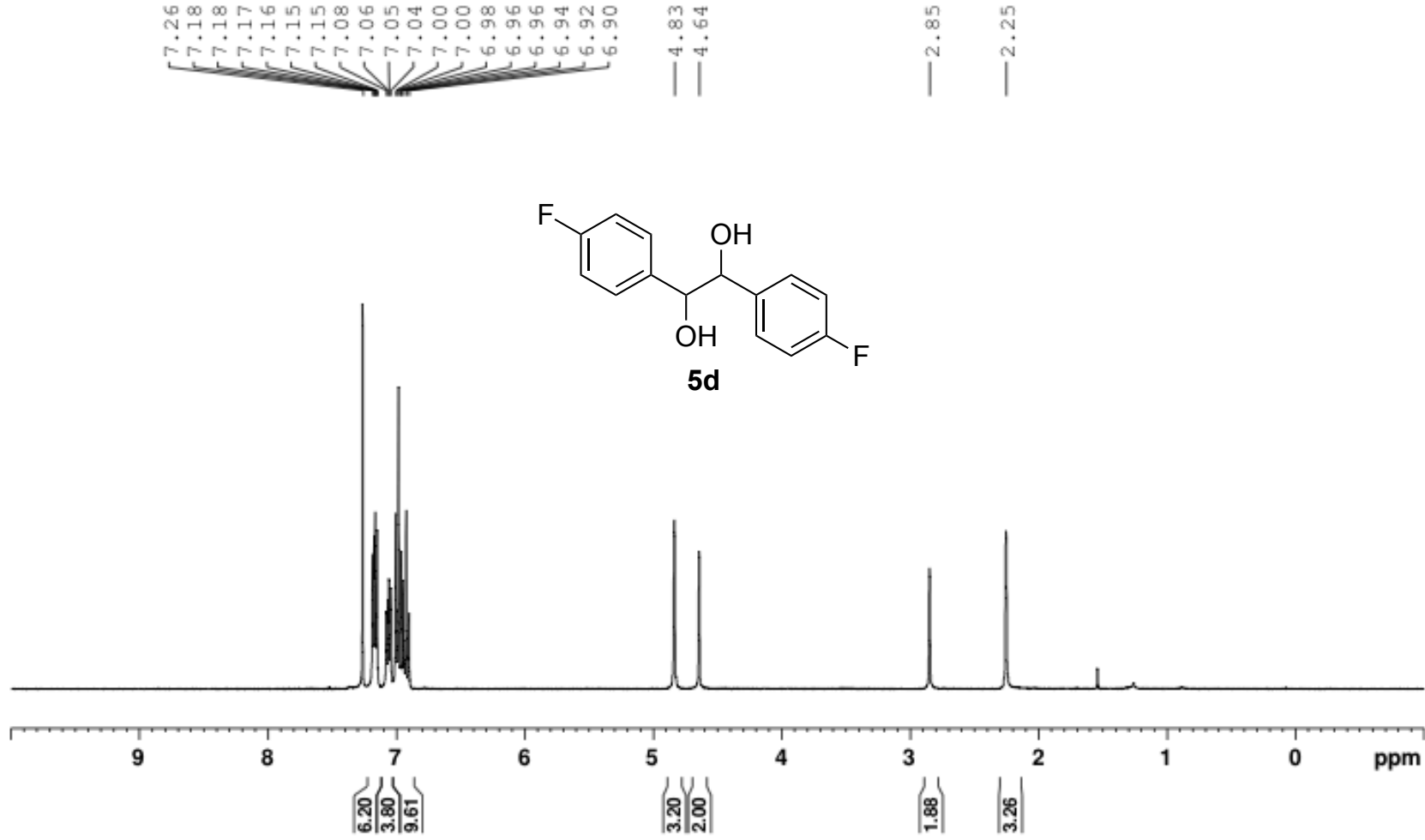
${ }^{1} \mathrm{H}$ NMR $\left(400 \mathrm{MHz}, \mathrm{CDCl}_{3}, \mathrm{rt}\right)$

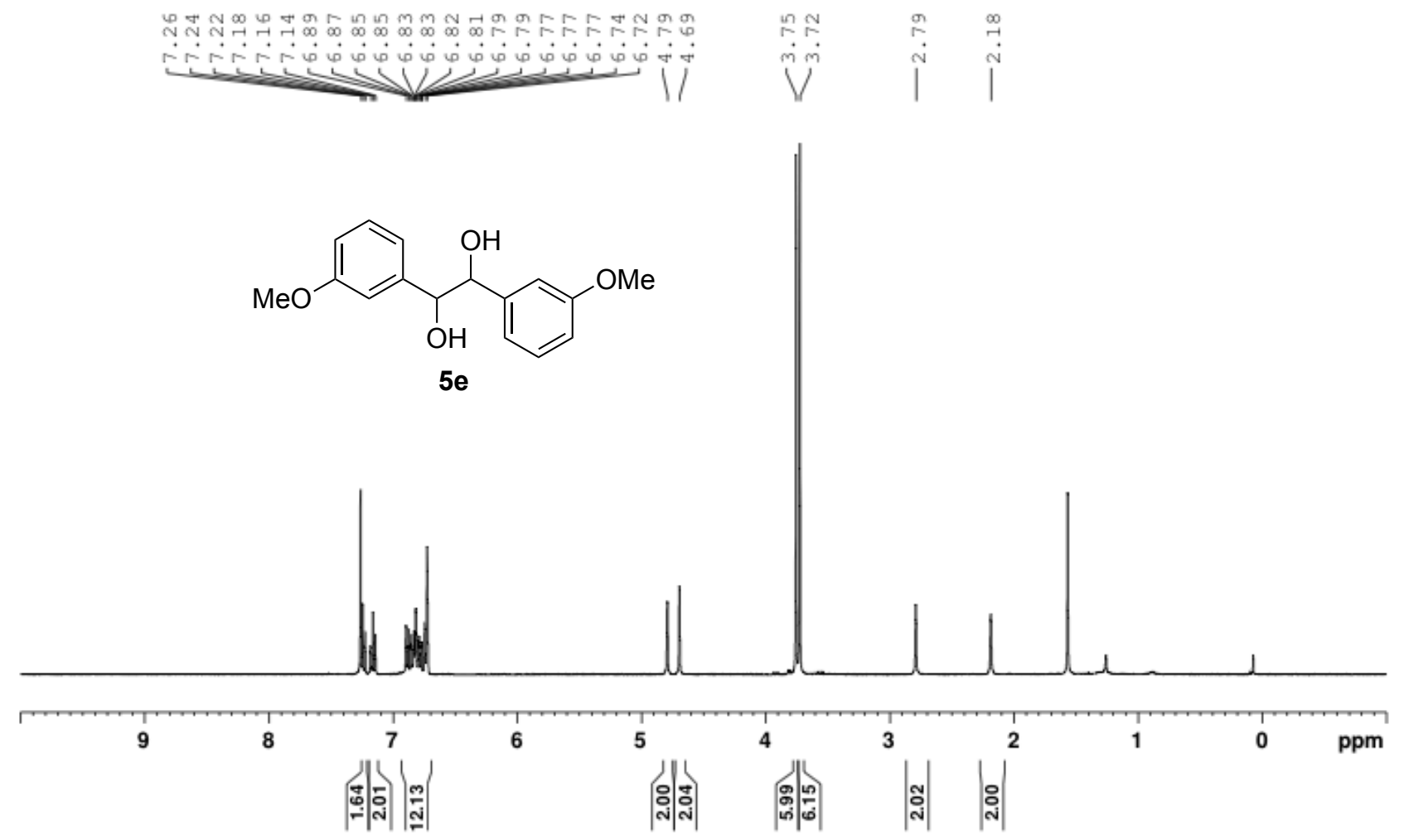

${ }^{1} \mathrm{H}$ NMR $\left(400 \mathrm{MHz}, \mathrm{CDCl}_{3}, \mathrm{rt}\right)$

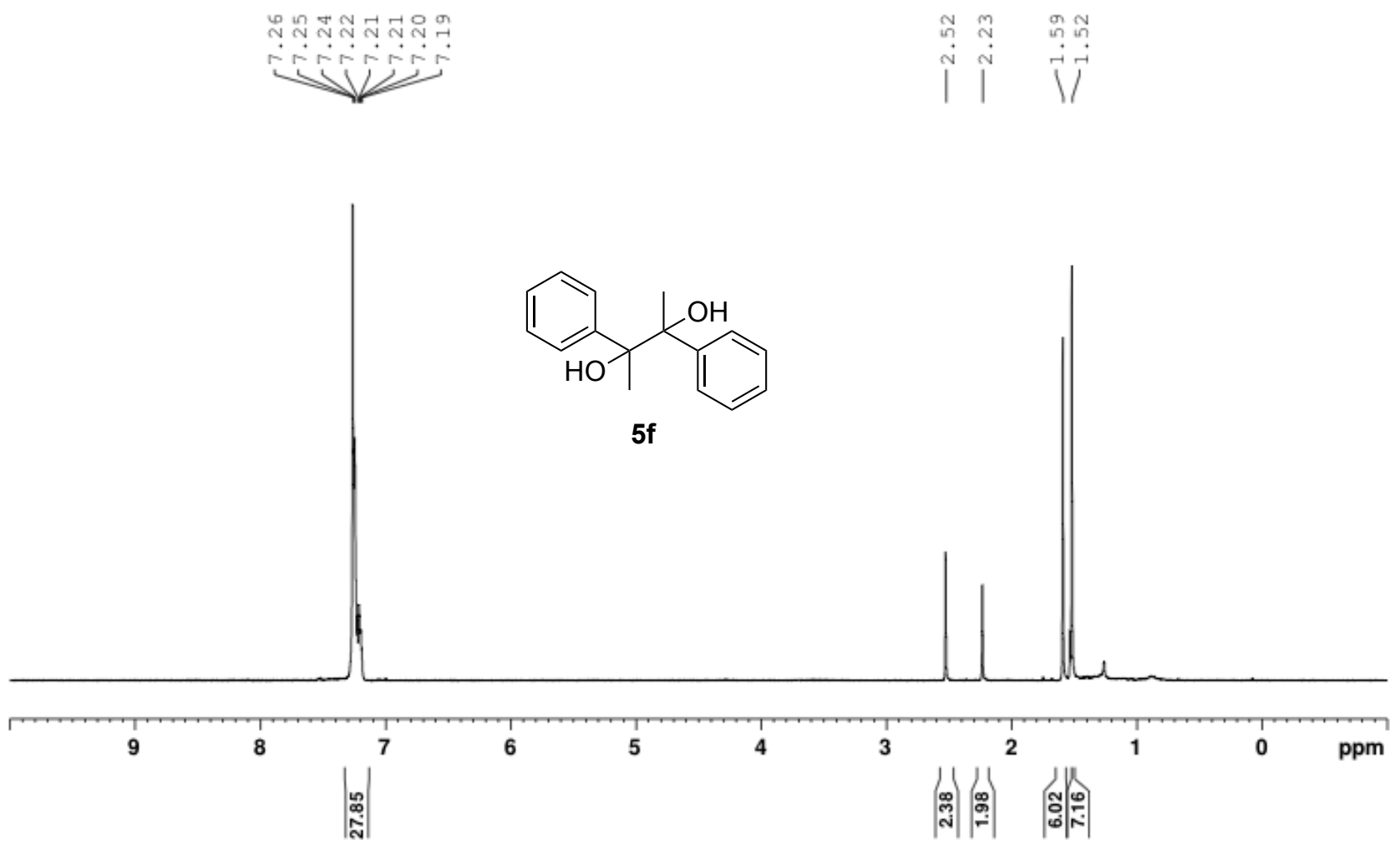


${ }^{1} \mathrm{H}$ NMR $\left(400 \mathrm{MHz}, \mathrm{CDCl}_{3}, \mathrm{rt}\right)$

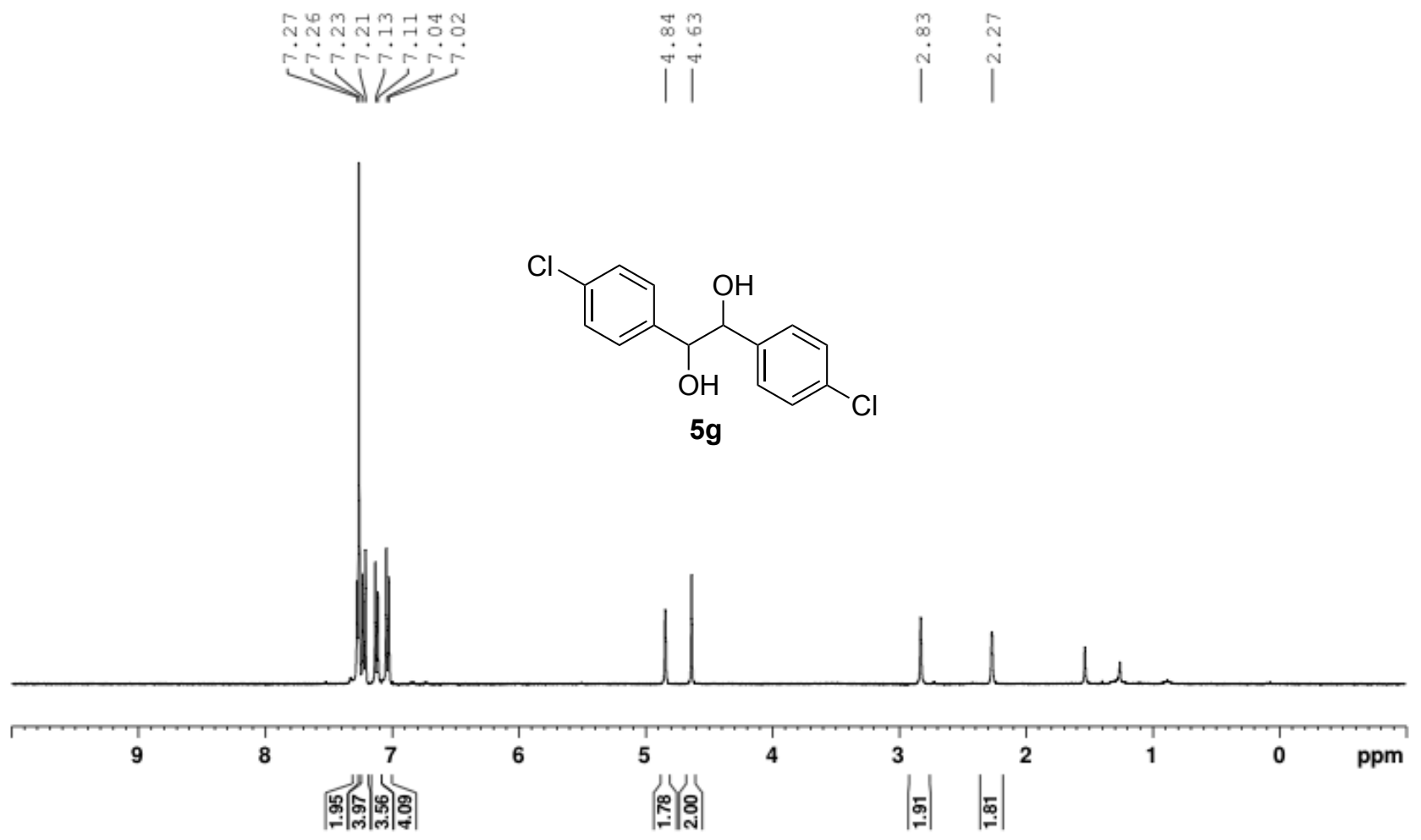

${ }^{1} \mathrm{H}$ NMR $\left(400 \mathrm{MHz}, \mathrm{CDCl}_{3}, \mathrm{rt}\right)$

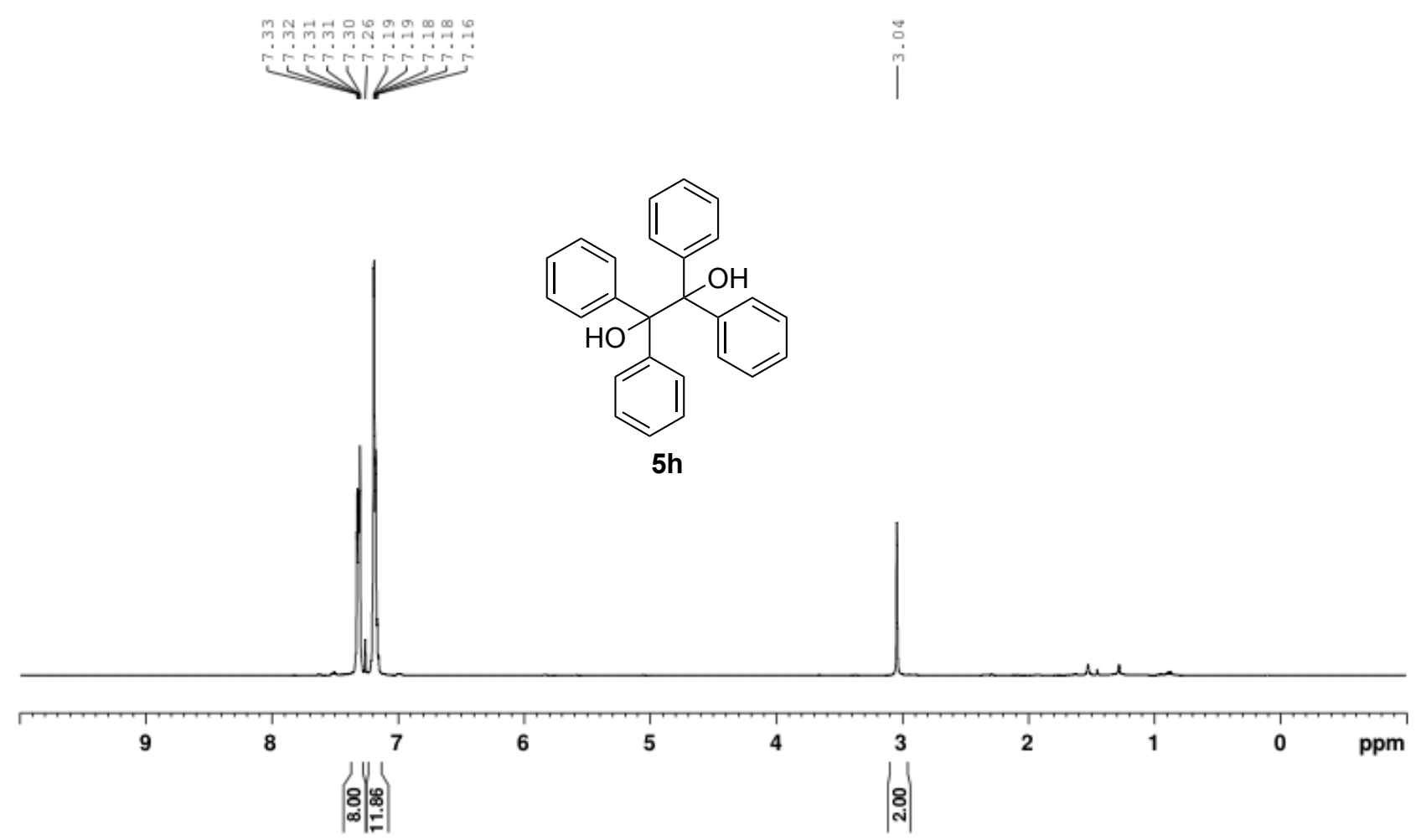


${ }^{1} \mathrm{H}$ NMR $\left(400 \mathrm{MHz}, \mathrm{CDCl}_{3}, \mathrm{rt}\right)$

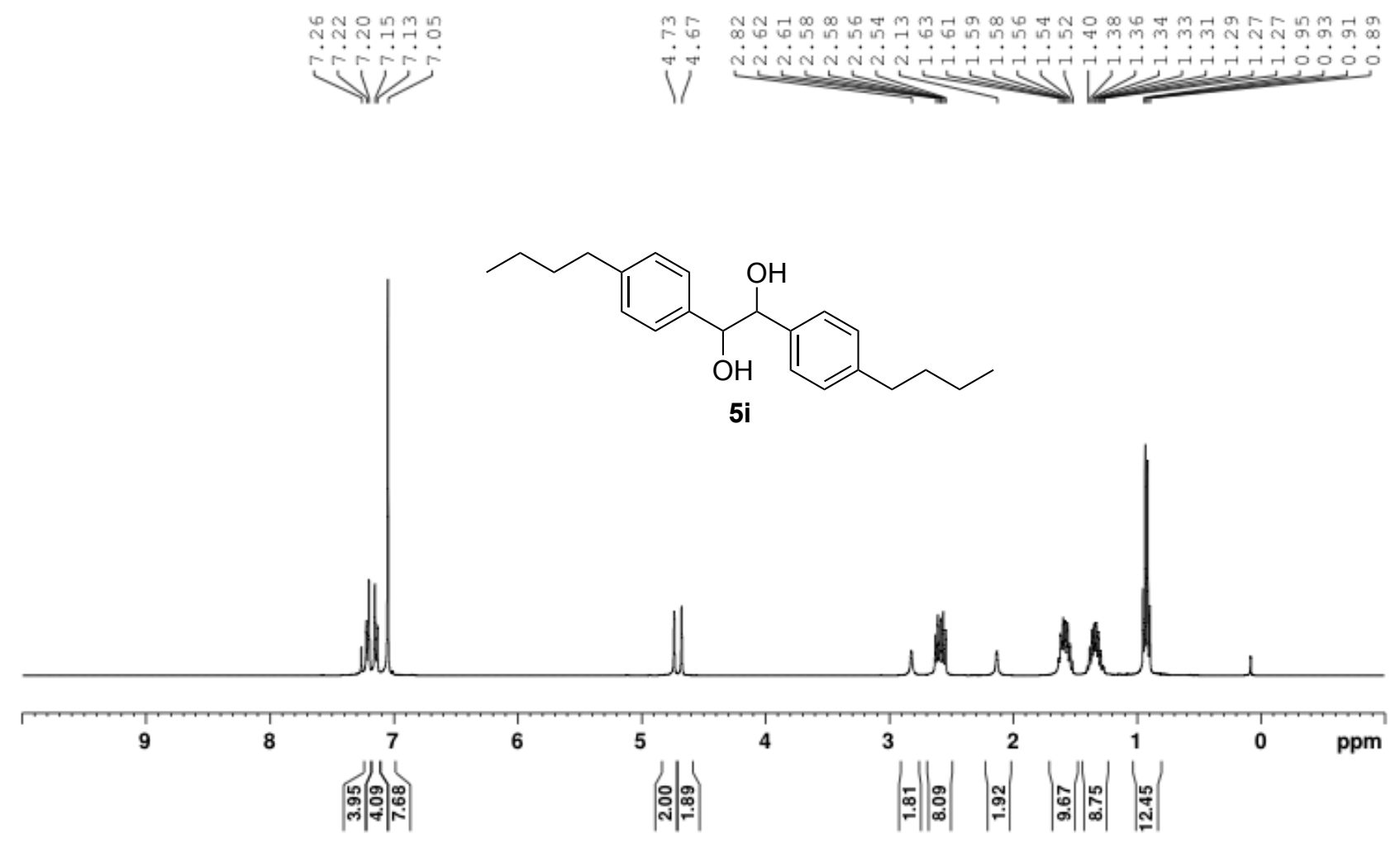

${ }^{13} \mathrm{C}$ NMR $\left(100 \mathrm{MHz}, \mathrm{CDCl}_{3}\right.$, rt $)$

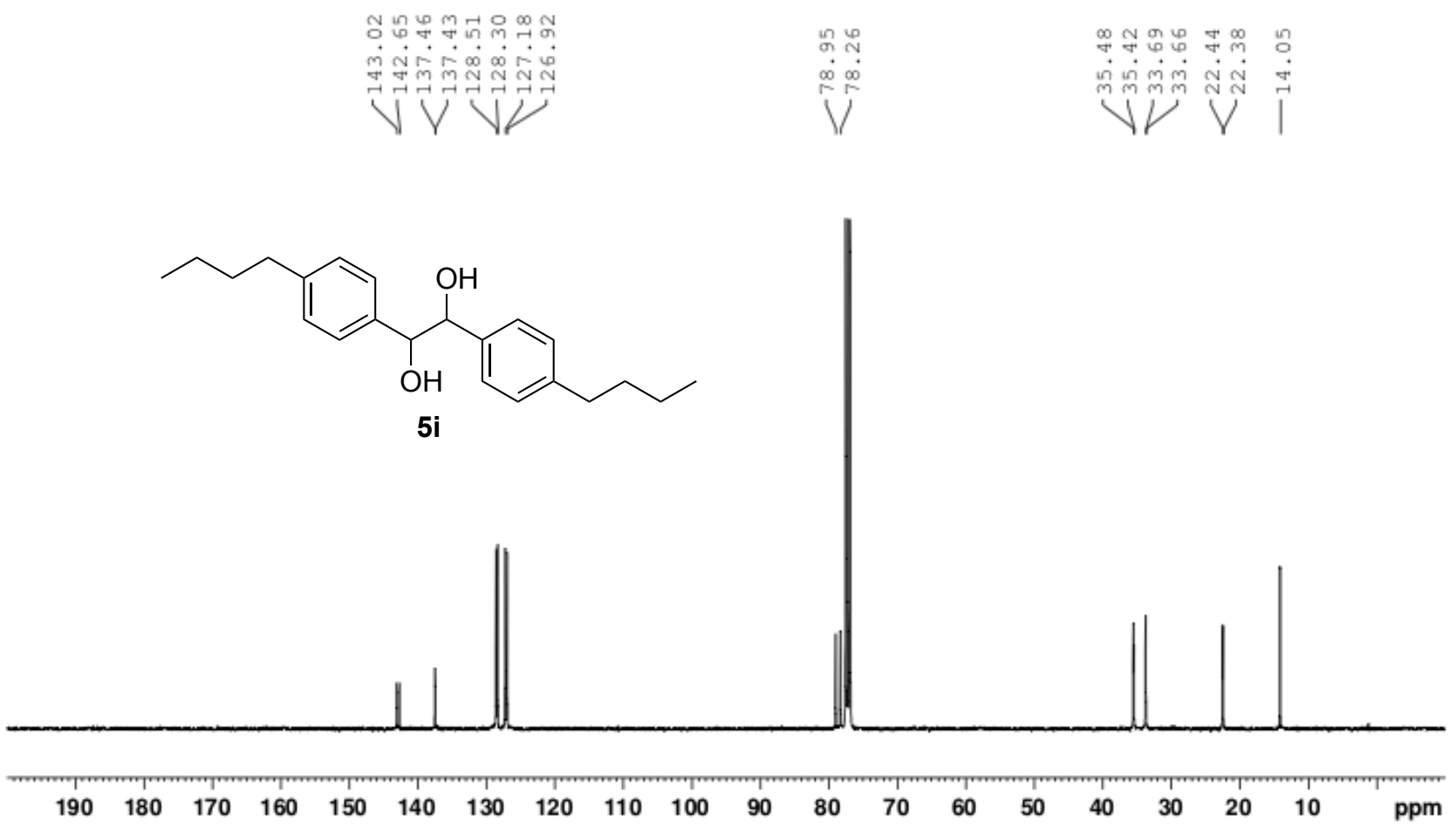


${ }^{1} \mathrm{H}$ NMR $\left(400 \mathrm{MHz}, \mathrm{CDCl}_{3}, \mathrm{rt}\right)$

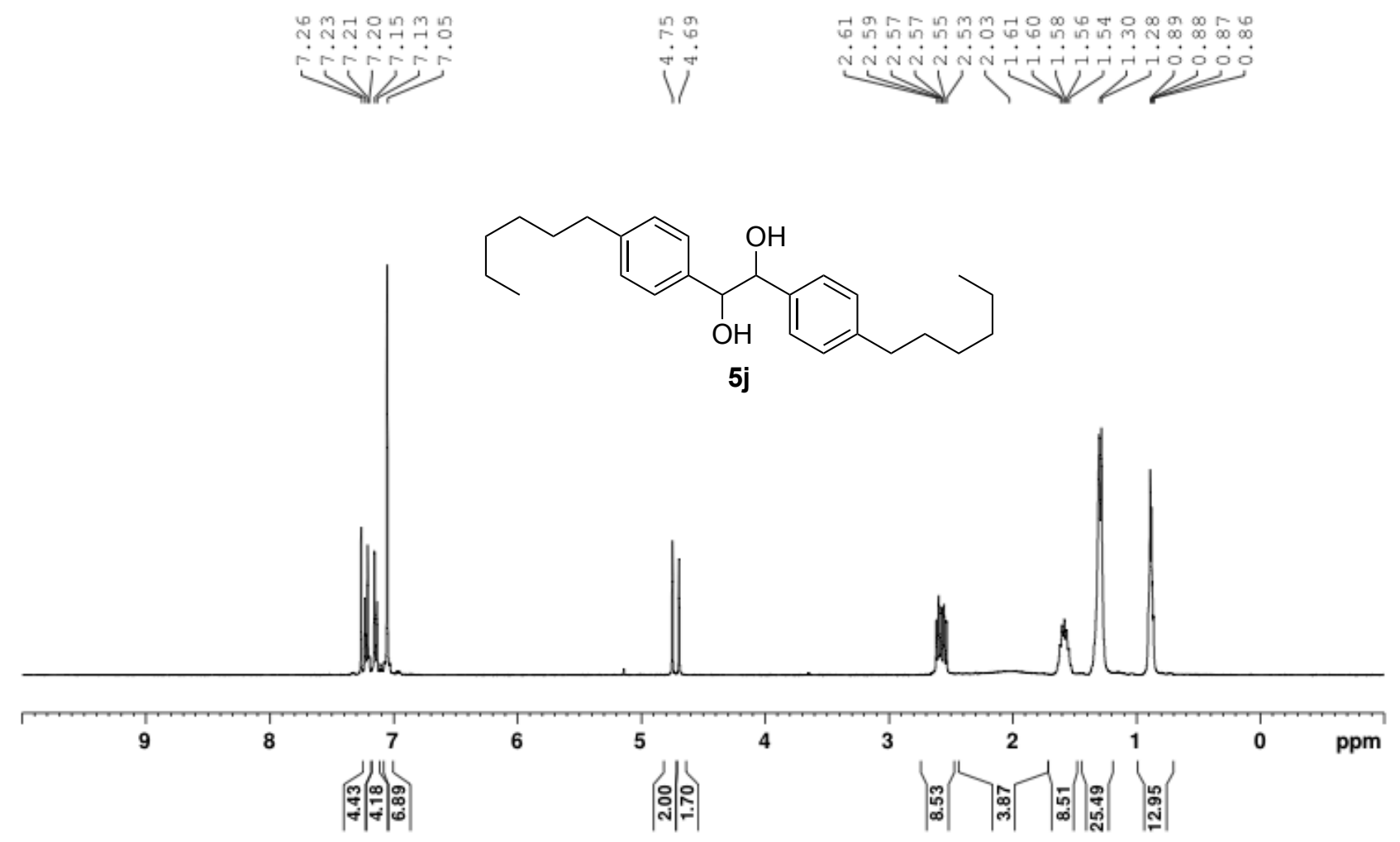

${ }^{13} \mathrm{C}$ NMR $\left(100 \mathrm{MHz}, \mathrm{CDCl}_{3}, \mathrm{rt}\right)$

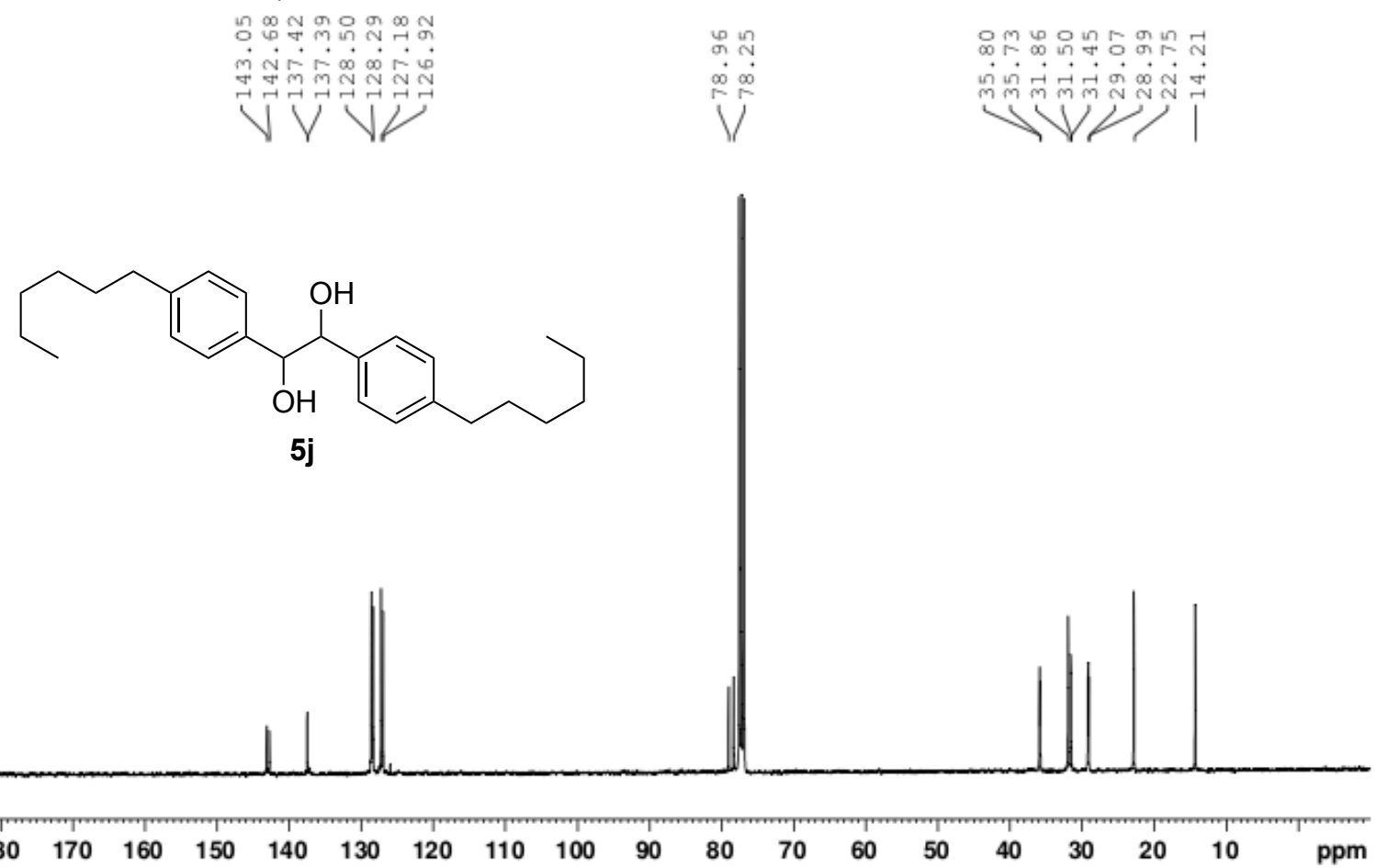


${ }^{1} \mathrm{H}$ NMR $\left(400 \mathrm{MHz}, \mathrm{CDCl}_{3}, \mathrm{rt}\right)$

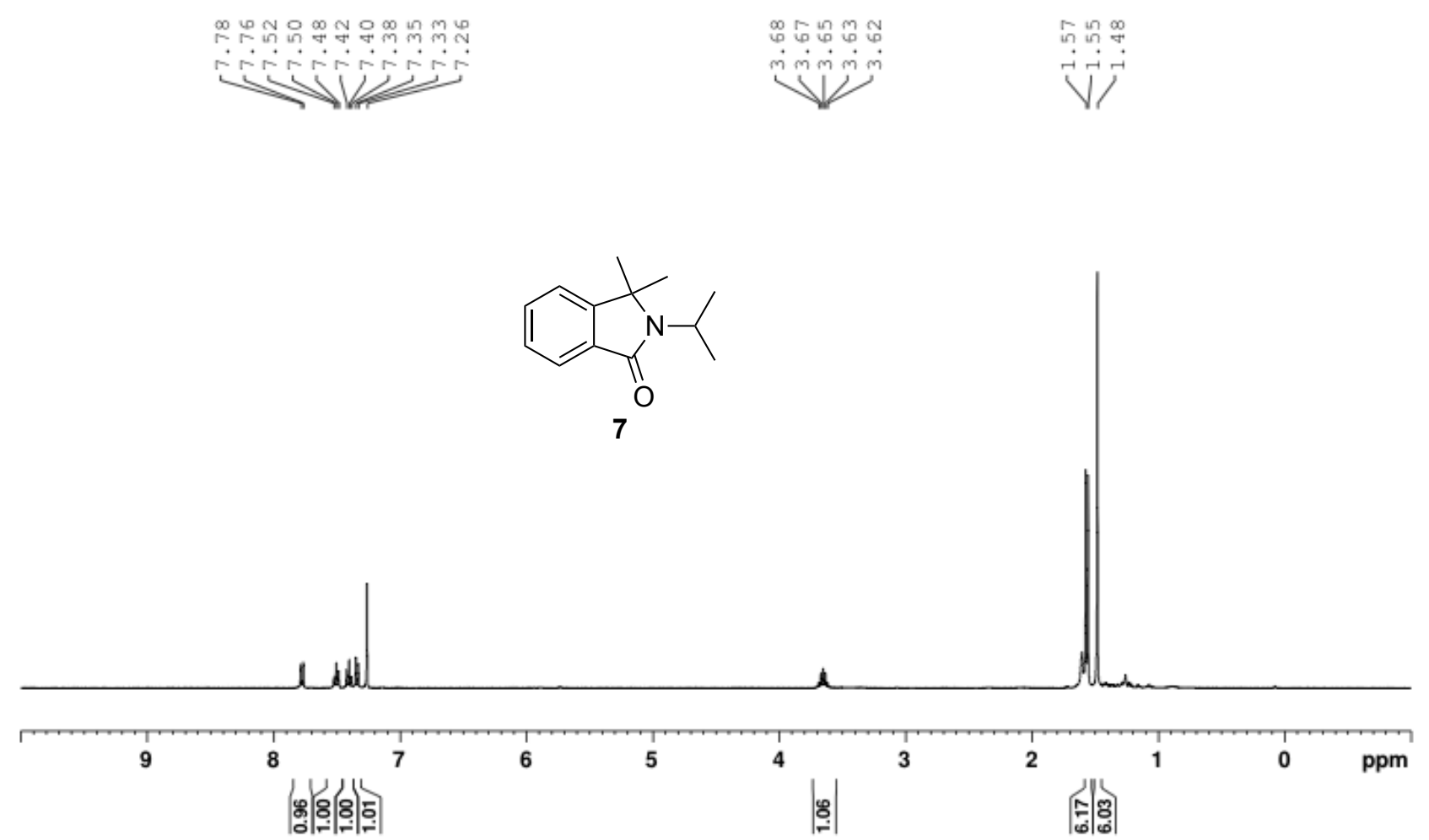

${ }^{1} \mathrm{H}$ NMR $\left(400 \mathrm{MHz}, \mathrm{CDCl}_{3}, \mathrm{rt}\right)$
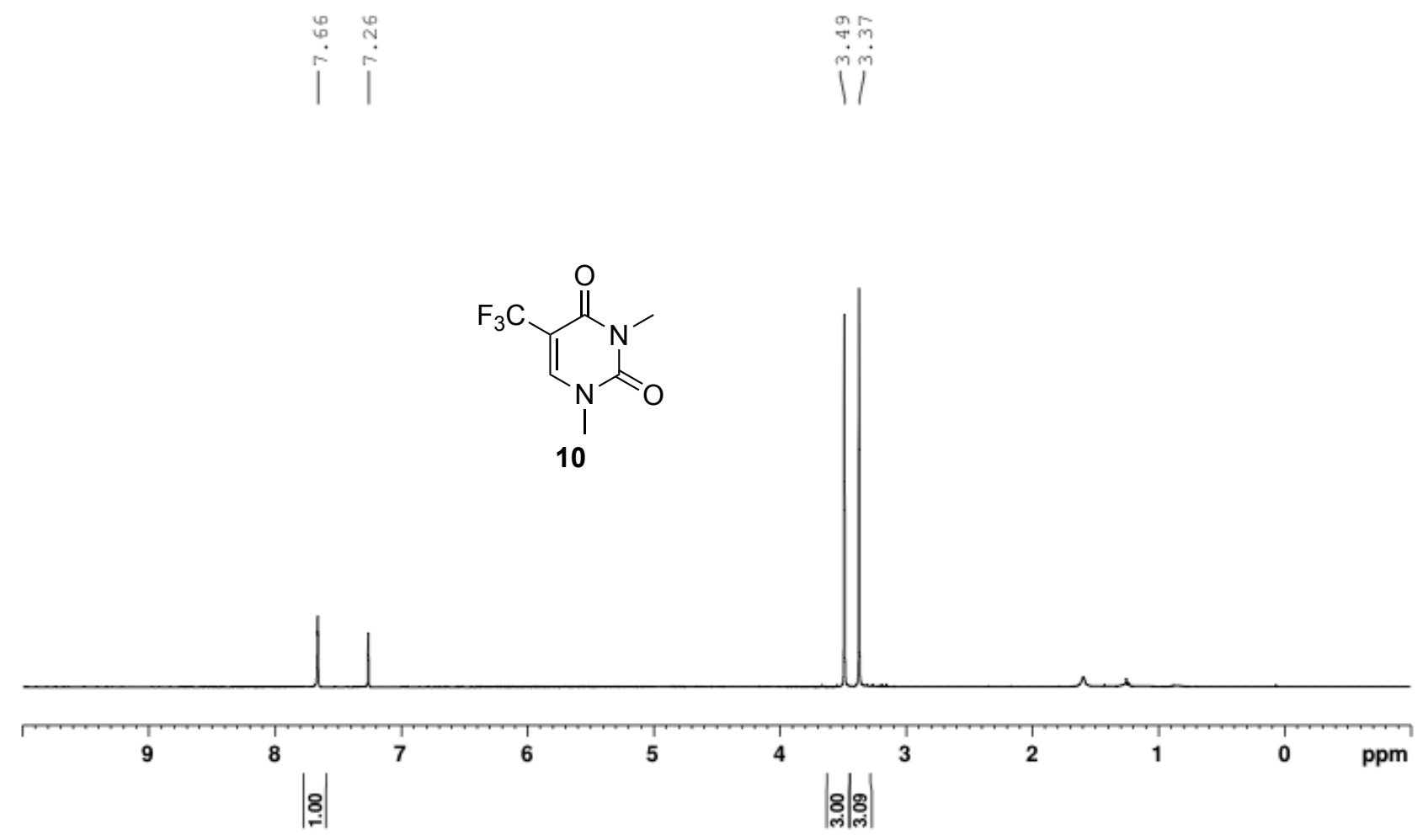
19F NMR (376 MHz, CDCl 3 , rt)

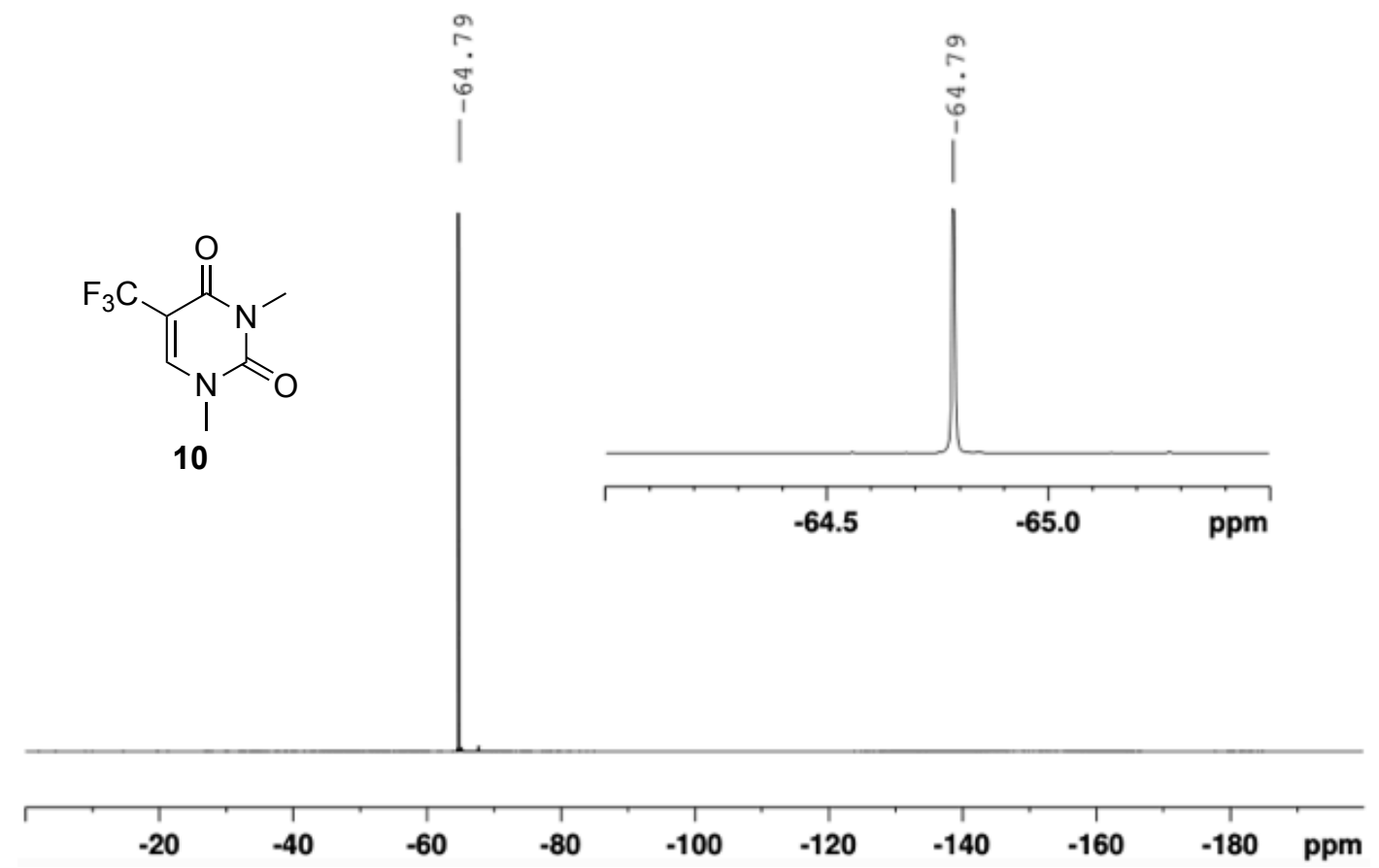

